\title{
Targeting the Overproduction of Peroxynitrite for the Prevention and Reversal of Paclitaxel-Induced Neuropathic Pain
}

\author{
Timothy Doyle, ${ }^{1}$ Zhoumou Chen, ${ }^{1}$ Carolina Muscoli, ${ }^{1,3,4}$ Leesa Bryant, ${ }^{1}$ Emanuela Esposito, ${ }^{5}$ Salvatore Cuzzocrea, ${ }^{5}$ \\ Concetta Dagostino, ${ }^{4}$ Jan Ryerse, ${ }^{2}$ Smita Rausaria, ${ }^{6}$ Andrew Kamadulski, ${ }^{6}$ William L. Neumann, ${ }^{6}$ \\ and Daniela Salvemini ${ }^{1}$ \\ Departments of ${ }^{1}$ Pharmacological and Physiological Science, and ${ }^{2}$ Pathology, Saint Louis University School of Medicine, St. Louis, Missouri $63104,{ }^{3}$ Faculty \\ of Pharmacy, University of Magna Graecia, Catanzaro, Italy 88100, ${ }^{4}$ Istituto Di Ricovero e Cura a Carattere Scientifico (IRCCS) San Raffaele La Pisana, \\ Rome, Italy 00163, ${ }^{5}$ Department of Clinical and Experimental Medicine and Pharmacology, IRCCS Centro Neurolesi Pulejo Messina Italy 98125, and \\ ${ }^{6}$ Department of Pharmaceutical Sciences, School of Pharmacy, Southern Illinois University Edwardsville, Edwardsville, Illinois 62026
}

Chemotherapy-induced peripheral neuropathy (CIPN) accompanied by chronic neuropathic pain is a major dose-limiting side effect of a large number of antitumoral agents including paclitaxel (Taxol). Thus, CIPN is one of most common causes of dose reduction and discontinuation of what is otherwise a life-saving therapy. Neuropathological changes in spinal cord are linked to CIPN, but the causative mediators and mechanisms remain poorly understood. We report that formation of peroxynitrite (PN) in response to activation of nitric oxide synthases and NADPH oxidase in spinal cord contributes to neuropathological changes through two mechanisms. The first involves modulation of neuroexcitatory and proinflammatory (TNF- $\alpha$ and IL-1 $\beta$ ) and anti-inflammatory (IL-10 and IL-4) cytokines in favor of the former. The second involves post-translational nitration and modification of glia-derived proteins known to be involved in glutamatergic neurotransmission (astrocyte-restricted glutamate transporters and glutamine synthetase). Targeting PN with PN decomposition catalysts (PNDCs) not only blocked the development of paclitaxel-induced neuropathic pain without interfering with antitumor effects, but also reversed it once established. Herein, we describe our mechanistic study on the role(s) of PN and the prevention of neuropathic pain in rats using known PNDCs (FeTMPyP ${ }^{5+}$ and MnTE-2-PyP ${ }^{5+}$ ). We also demonstrate the prevention of CIPN with our two new orally active PNDCs, SRI6 and SRI110. The improved chemical design of SRI6 and SRI110 also affords selectivity for PN over other reactive oxygen species (such as superoxide). Our findings identify PN as a critical determinant of CIPN, while providing the rationale toward development of superoxide-sparing and "PN-targeted" therapeutics.

\section{Introduction}

Paclitaxel (Taxol) is a widely used chemotherapeutic indicated for treating breast, ovarian, and non-small cell lung carcinomas and Kaposi's sarcoma. Unfortunately, the dose-limiting side effect and leading cause of discontinuation of this highly efficacious antitumor drug is peripheral neuropathy accompanied by chronic neuropathic pain that resolves within weeks, months, or years after drug termination (Cata et al., 2006b; Farquhar-Smith, 2011). The clinical management of these patients becomes diffi-

Received Dec. 20, 2011; revised March 1, 2012; accepted March 2, 2012.

Author contributions: W.L.N. and D.S. designed research; T.D., Z.C., C.M., L.B., E.E., S.C., C.D., J.R., S.R., and A.K. performed research; T.D. and S.R. analyzed data; W.L.N. and D.S. wrote the paper.

This work was supported by grants from NIH-NIDA (DA024074) and NIH-NIAMS (AR058231). We acknowledge the contributions of Dr. Ines Batinić-Haberle for the synthesis of MnTE-2-PyP ${ }^{5+}$ and Christopher Kriedt for his work in measuring the antitumor effects of paclitaxel. We are grateful to Dr. Gary Bennett for his invaluable advice throughout the course of these studies and for critically reviewing our work.

The authors declare no competing financial interests.

Correspondence should be addressed to Daniela Salvemini, Department of Pharmacological and Physiological Science, Saint Louis University School of Medicine, 1402 South Grand Boulevard, St. Louis, M0 63104. E-mail: salvemd@slu.edu.

DOI:10.1523/JNEUROSCI.6343-11.2012

Copyright $\odot 2012$ the authors $\quad 0270-6474 / 12 / 326149-12 \$ 15.00 / 0$ cult as current pain drugs are marginally effective and display unacceptable side effects (Farquhar-Smith, 2011). Understanding the underlying causative mechanisms is of paramount significance to identifying novel ways to minimize this side effect and maximize antitumor effects.

Peroxynitrite $(\mathrm{PN})$, the reaction product of superoxide (SO) and nitric oxide (NO) (Beckman et al., 1990), is a potent proinflammatory and pronociceptive species implicated in pain of several etiologies (for review, see Salvemini et al., 2011). In these settings, two glial pathways underlie $\mathrm{PN}^{\prime}$ s effects in spinal cord: increased TNF- $\alpha$ and IL- $1 \beta$ contributing to hypersensitivity in dorsal horn neurons (for review, see DeLeo and Yezierski, 2001; Watkins et al., 2001; Milligan and Watkins, 2009) and posttranslational nitration of the glutamate transporter (GT), GLT-1, and glutamine synthetase (GS), key regulators of optimal synaptic glutamate homeostasis (Kugler, 1993). PN-mediated nitration of these proteins inactivates their biological function, thus enhancing glutamatergic neurotransmission (Trotti et al., 1996, 1999; Miñana et al., 1997; Görg et al., 2005). It is noteworthy that increased glial-derived cytokines (Ledeboer et al., 2006; Peters et al., 2007) and altered glutamatergic neurotransmission (Weng et 
al., 2005; Cata et al., 2006a; Zhang et al., 2012) are associated with paclitaxel-induced neuropathic pain; however, the mechanism(s) responsible remains largely unknown. Thus, it is possible that increased spinal PN following paclitaxel treatment triggers such neuropathological events. Our results reveal that overt spinal formation of PN following nitric oxidase synthase (NOS) and NADPH oxidase activation and manganese superoxide dismutase (MnSOD) inactivation contributes to neuropathic pain by increasing TNF- $\alpha$ and IL- $1 \beta$ and engaging in post-translational nitration of GLT-1 and GS. Removing PN with well characterized peroxynitrite decomposition catalysts (PNDCs), FeTMPyP ${ }^{5+}$ and MnTE-2-PyP ${ }^{5+}$ (Salvemini et al., 1998; Batinic-Haberle et al., 2010), blocked these changes and neuropathic pain without interfering with antitumor effects and, importantly, reversed established pain.

Current PNDCs are nonselective with equal catalytic activities toward both PN and SO (Salvemini et al., 1998; Batinic-Haberle et al., 2010); making it difficult to decipher each species' contribution in pathophysiological settings. Moreover, the lack of oral bioavailability can restrict their chronic use (for review, see Salvemini et al., 2011). Evidence also indicates the importance of SO in learning and memory (Massaad and Klann, 2010), while PN has no known benefit. Therefore, targeting PN while sparing SO may provide a better strategy for designing molecules that dissect PN signaling pathways without compromising important physiological pathways. Our chemical design paradigm pairing PNDC selectivity with enhanced drug-like properties led to orally bioavailable and "SO-sparing" PNDCs, SRI110 (Rausaria et al., 2011a) and SRI6 (Rausaria et al., 2011b), which block and reverse neuropathic pain. Selective "PN-targeted" approaches may open new translational pathways for developing pain therapies and maximize chemotherapeutic doses.

\section{Materials and Methods}

\section{Materials}

Paclitaxel was purchased from Parenta Pharmaceuticals. FeTMPyP ${ }^{5+}$ was obtained from Cayman Chemical, whereas the MnTE-2-PyP ${ }^{5+}$ was provided by Dr. I. Batinić-Haberle (Duke University, Durham, NC). For cell culture: media (DMEM and McCoy's 5A) were purchased from Mediatech, FBS from Thermo Scientific Hyclone, and the penicillin/ streptomycin from Invitrogen. For immunofluorescence, immunoprecipitation, and Western blot, the antibodies were from the following sources: anti-NT antibody was a kind gift from Dr. H. Ischiropoulos (The Children's Hospital of Philadelphia Research Institute, Philadelphia, PA); goat anti-rabbit rhodamine from Invitrogen; mouse monoclonal anti-glutamine synthetase from BD Biosciences; polyclonal rabbit antiGLT-1 from Alpha Diagnostic; rabbit polyclonal anti-MnSOD from Millipore; mouse anti-GFAP from Santa Cruz Biotechnology; monoclonal mouse anti-OX-42 from Millipore; monoclonal mouse anti- $\beta$-actin from Sigma; and horseradish peroxidase-conjugated anti-mouse and anti-rabbit secondary antibodies from Thermo Fisher Scientific. FluoroGel II with DAPI was purchased from Electron Microscopy Sciences. The enhanced chemiluminescence reagents were from GE Healthcare Life Sciences (ECL) or Thermo Fisher Scientific. Rat brain lysate was purchased from Millipore. Unless otherwise stated, all other chemicals were purchased from Sigma.

\section{Experimental animals}

Male Sprague Dawley rats (200-220 g starting weight) from Harlan were housed 3-4 per cage in a controlled environment (12 h light/dark cycle) with food and water available ad libitum. All experiments were performed in accordance with the International Association for the Study of Pain and the National Institutes of Health guidelines on laboratory animal welfare and the recommendations by Saint Louis University Institutional Animal Care and Use Committee.

\section{Chemotherapy-induced neuropathic pain}

Paclitaxel or its vehicle (Cremophor EL and 95\% dehydrated ethanol in $1: 1$ ratio) was injected intraperitoneally on four alternate days $(2 \mathrm{mg} / \mathrm{kg}$ on days $0,2,4$, and 6 with a final cumulative dose of $8 \mathrm{mg} / \mathrm{kg}$ ) (Polomano et al., 2001). Experimental test substances or their vehicle were given either subcutaneously (s.c., $0.2 \mathrm{ml}$ ), orally by gavage (p.o., $0.2 \mathrm{ml}$ ) or by intrathecal injection ( $10 \mu \mathrm{l}$ followed by a $10 \mu \mathrm{l}$ flush with sterile physiological saline) in rats chronically implanted with intrathecal cannulas using the L5/L6 lumbar approach, as described previously by us and others (Størkson et al., 1996; Ledeboer et al., 2007; Doyle et al., 2010; Muscoli et al., 2010) and commonly used for drug delivery (SchoenigerSkinner et al., 2007; Doyle et al., 2010; Muscoli et al., 2010; Ramos et al., 2010). Test compounds were administered from day 0 (D0) (30 min before the first intraperitoneal injection of the chemotherapeutic agent) to D15 or were given once on D16.

\section{Behavioral testing}

The behavioral responses in this model last for months, thus modeling painful neuropathies in patients (Polomano et al., 2001). Behavioral testing was done with the experimenters blinded to treatment conditions. All animals were allowed to acclimate for $\sim 15 \mathrm{~min}$. If testing coincided with a day when rats received their drugs, behavioral testing was done always before the injection of the test substance.

Mechano-allodynia. Mechanical withdrawal thresholds were taken using calibrated von Frey filaments [Stoelting, ranging from $3.61(0.407 \mathrm{~g})$ to $5.46(26 \mathrm{~g})$ bending force] according to the "up-and-down" method (Dixon, 1980). The development of mechano-allodynia is evidenced by a significant $(p<0.05)$ reduction in mechanical mean absolute pawwithdrawal thresholds $(g)$ at forces that failed to elicit withdrawal responses before the administration of the chemotherapeutic treatment (baseline).

Mechano-hyperalgesia. Mechanical withdrawal threshold was measured by the Randall and Sellitto paw pressure test (Randall and Selitto, 1957) using an analgesiometer (Ugo Basile), which applies a linearly increasing mechanical force to the dorsum of the rat's hindpaw. The nociceptive threshold was defined as the force $(g)$ at which the rat withdrew its paw (cutoff set at $250 \mathrm{~g}$ ). Paclitaxel treatment results in bilateral allodynia and hyperalgesia (Polomano et al., 2001). Since the thresholds did not differ between left and right hindpaws at any time point in any group, values from both paws were averaged for further analysis and data presentation. None of the animals exhibited obvious signs of toxicities; i.e., they exhibited normal posture, grooming, locomotor behavior, hair coat was normal without signs of piloerection or porphyrin, and body weight gain was normal and comparable to vehicle-treated rats.

\section{$E D_{50}$ determination}

The effective dose providing 50\% inhibition of allodynia or hyperalgesia was determined using a 4-parameter variable slope nonlinear regression analysis of the $\%$ Inhibition using GraphPad Prism v5.03. \% Inhibition = $\left(\mathrm{PWT}_{\mathrm{PNDC}}-\mathrm{PWT}_{\text {paclitaxel }}\right) /\left(\mathrm{PWT}_{\mathrm{Veh}}-\mathrm{PWT}_{\text {paclitaxel }}\right) \times 100$, where PWT = Paw Withdrawal Threshold, PNDC $=$ peroxynitrite decomposition catalyst at a particular dose, and $\mathrm{Veh}=$ vehicle.

\section{Immunofluorescence detection}

After behavioral measurements, rats were anesthetized with ketamine/ xylazine and intracardially perfused with freshly prepared $4 \%$ paraformaldehyde in $0.1 \mathrm{~m}$ sodium phosphate buffer, pH 7.4. The spinal cord (L4-L6) was removed and fixation continued in the same fixative for $16 \mathrm{~h}$ at $4^{\circ} \mathrm{C}$. After washing in PBS ( $\mathrm{pH} 7.4$ ), the tissue was infiltrated with $30 \%(\mathrm{w} / \mathrm{v})$ sucrose in PBS at $4^{\circ} \mathrm{C}$ for $24 \mathrm{~h}$, washed again in PBS, transferred to OCT, and snap frozen in liquid nitrogen. Transverse sections $(10 \mu \mathrm{m})$ were cut in a cryostat, collected on glass microscope slides, and stored at $-20^{\circ} \mathrm{C}$ until used for immunofluorescent detection of nitrotyrosine (NT) as we reported previously (Wang et al., 2004; Muscoli et al., $2007,2010)$. The sections were blocked, then labeled with a well characterized affinity-purified rabbit polyclonal anti-NT antibody (1:150) (Fries et al., 2003) in 1/10th blocking buffer for $3 \mathrm{~h}$ at room temperature (RT) or $16 \mathrm{~h}$ at $4^{\circ} \mathrm{C}$. The sections were rinsed in PBS and target proteins detected with goat anti-rabbit rhodamine $(1: 400)$ in $1 / 10$ th blocking buffer for $1 \mathrm{~h}$ at RT in a humidified container. Following several PBS 
rinses, the sections were mounted in Fluoro-Gel II with DAPI, coverslipped, and photographed with an Olympus FV1000 confocal microscope at the same settings across all groups. Additional sections were treated with normal rabbit IgG at concentrations equivalent to those of the primary antibodies as controls and yielded only nonspecific background fluorescence. The immunohistochemical results shown in Figure 3 (see below) are representative examples of 3 or more separate immunostaining reactions in 3 different animals in which similar results were obtained. The micrographs were taken from the superficial layer of the dorsal horn of the spinal cord. Post-acquisition adjustments were applied equally between all groups. The results were analyzed by qualitative inspection of the staining patterns and fluorescence intensity in saved digital images.

\section{Immunoprecipitation and immunoblotting}

Cytosolic fractions and P2 membranes were obtained as previously described (Takagi et al., 2000; Wang et al., 2004; Muscoli et al., 2007) and stored immediately at $-80^{\circ} \mathrm{C}$. Immunoprecipitation and Western blot analyses were performed as described previously (Takagi et al., 2000; Wang et al., 2004; Muscoli et al., 2007). Proteins were resolved with $7.5 \%$ (GLT-1), $10 \%$ (glutamine synthetase), or $4-20 \%$ (MnSOD) SDS-PAGE before electrophoretic transfer. Membranes were blocked for $1 \mathrm{~h}$ at RT in $1 \%$ BSA in TBS-T ( 50 mm Tris- $\mathrm{HCl}, \mathrm{pH}$ 7.4), $150 \mathrm{~mm} \mathrm{NaCl}, 0.01 \%$ Tween- 20 and $0.1 \%$ thimerosal) and then probed with mouse monoclonal anti-glutamine synthetase (1:2000), polyclonal rabbit anti-GLT-1 (1:1000), rabbit polyclonal antiMnSOD (1:1000), mouse GFAP (1:1000), or mouse monoclonal OX-42 (1:1000). Membranes were washed with TBS/T and visualized with horseradish peroxidase-conjugated secondary antibodies for $1 \mathrm{~h}$ at RT and enhanced chemiluminescence. Rat brain lysate containing our proteins of interest was used as positive control. The blots were stripped and probed with a murine monoclonal anti- $\beta$-actin antibody (1:2000). The relative density of the protein bands of interest were determined from film using ImageQuant 5.2 software (Molecular Dynamics) and normalized to $\beta$-actin bands.

\section{Measurement of nitric oxide synthase activity}

Spinal cords were homogenized in HEPES buffer $(20 \mathrm{~mm}, \mathrm{pH} 7.2$, containing $320 \mathrm{~mm}$ sucrose, $1 \mathrm{~mm}$ DL-dithiothreitol, $10 \mu \mathrm{g} / \mathrm{ml}$ soybean trypsin inhibitor, $2 \mu \mathrm{g} / \mathrm{ml}$ aprotinin, and $10 \mu \mathrm{g} / \mathrm{ml}$ leupeptin). The cytosolic fractions were collected by centrifuging at $100,000 \times g$ (L8 -70 ultracentrifuge, Beckman) for $30 \mathrm{~min}$ at $4^{\circ} \mathrm{C}$ and stored at $-70^{\circ} \mathrm{C}$ up to $10 \mathrm{~d}$. Protein concentration in the cytosolic fractions was measured spectrophotometrically against a bovine serum albumin standard (Salter et al., 1991). NOS activity was evaluated by measuring the rate of conversion of $\mathrm{L}-\left[U_{-}{ }^{14} \mathrm{C}\right]$ arginine to citrulline, according to the method of Salter et al. (1991). Briefly, cytosolic fractions (100 $\mu \mathrm{g}$ of protein) were incubated for $10 \mathrm{~min}$ at $37^{\circ} \mathrm{C}$ in potassium phosphate buffer [ $50 \mathrm{~mm}, \mathrm{pH} 7.2$, containing (in mM): $60 \mathrm{~L}$-valine, $120 \mu \mathrm{M} \mathrm{NADPH}, 1.2 \mathrm{~L}$-citrulline, $1.2 \mathrm{MgCl}_{2}$, and $0.24 \mathrm{CaCl}_{2}$ in the presence of test compounds (0.01-1 mM) or vehicle]. Samples were then incubated for $10 \mathrm{~min}$ at $37^{\circ} \mathrm{C}$ with $\mathrm{L}-\left[\mathrm{U}_{-}{ }^{14} \mathrm{C}\right]$ arginine (150,000 dpm, specific activity $304 \mathrm{mCi} / \mu \mathrm{mol}$, NEN Life Science) and 20 $\mu \mathrm{M} \mathrm{L}$-arginine. The reaction was stopped by the addition of $1.0 \mathrm{ml}$ of a mixture of $\mathrm{H}_{2} \mathrm{O} /$ Dowex-50W 1:1 v/v (200-400, 8\% cross-linked, $\mathrm{H}^{+}$form). The $\mathrm{Na}^{+}$-form of Dowex-50W was prepared by washing the $\mathrm{H}^{+}$form of resin four times with $1 \mathrm{~m} \mathrm{NaOH}$ and then with bidistilled water until the $\mathrm{pH}$ was $<7.5$. The sample/resin was centrifuged $(11,000 \times g$ for $3 \mathrm{~min}$ ) and an aliquot of the supernatant was taken for scintillation counting (in $4 \mathrm{ml}$ of Pico-Aqua; PerkinElmer). The activity of constitutive $\mathrm{Ca}^{2+}$-dependent NOS was determined from the difference between the labeled citrulline produced by control samples and samples containing 1 mM EGTA; the activity of inducible $\mathrm{Ca}^{+2}$-independent enzyme was determined from the difference between the labeled citrulline produced by samples containing 1 mм EGTA and samples containing 1 mM EGTA plus $1 \mathrm{~mm} N^{G}$-monomethyl-L-arginine. The activity of both isoforms was expressed as $\mathrm{nmol} / \mathrm{min} / \mathrm{mg}$ protein.

\section{Measurement of NADPH oxidase activity}

Spinal cord tissues (L4-L6) were homogenized in HEPES buffer (10 mM, $\mathrm{pH} 7.5$, containing $250 \mathrm{~mm}$ sucrose, $1 \mathrm{~mm}$ EGTA, $25 \mathrm{~mm}$ potassium chloride, $10 \mu \mathrm{g} / \mathrm{ml}$ soybean trypsin inhibitor, $2 \mu \mathrm{g} / \mathrm{ml}$ aprotinin and 10 $\mu \mathrm{g} / \mathrm{ml}$ leupeptin) and centrifuged at $1000 \times g$ to obtain the nuclear-free supernatants. The NADPH cytochrome $c$ reductase activity in these supernatants was measured using Cytochrome $c$ Reductase (NADPH) Assay Kit following the manufacturer's instructions.

Measurement of mitochondrial MnSOD activities in spinal cord Spinal cord tissues from lumbar region enlargement (L4-L6) were homogenized with $10 \mathrm{~mm}$ PBS, pH 7.4, sonicated on ice for $1 \mathrm{~min}(20 \mathrm{~s}, 3$ times), and centrifuged at $1100 \times g$ for $10 \mathrm{~min}$. The SOD activity in the supernatants was measured, as described previously (Wang et al., 2004), by the ability to competitively inhibit xanthine-xanthine oxidase-derived superoxide reduction of NBT to blue tetrazolium salt. Copper, zinc SOD $(\mathrm{Cu}, \mathrm{ZnSOD})$ activity was blocked in this assay by the addition of $2 \mathrm{~mm}$ $\mathrm{NaCN}$ after preincubation for $30 \mathrm{~min}$. The rate of NTB reduction was monitored spectrophotometrically (PerkinElmer Lambda 5 Spectrophotometer) at $560 \mathrm{~nm}$. The amount of protein required to inhibit the rate of NTB reduction by $50 \%$ was defined as one unit of enzyme activity. Enzymatic activity was expressed in units per milligram of protein (Wang et al., 2004).

\section{Cytokine ELISA}

Spinal cord levels of TNF- $\alpha$, IL-1 $\beta$, IL-10, and IL-4 were measured using commercially available ELISA kits (R\&D Systems) according to the manufacturer's protocol.

\section{Antitumor activity of paclitaxel}

The effects of MnTE-2-PyP ${ }^{5+}$ on antitumor activity of paclitaxel on well characterized human breast cancer cells (SKBR3) (Swift et al., 2010; Itamochi et al., 2011) and human ovarian cancer cells (SKOV3) (Lacroix and Leclercq, 2004; Swift et al., 2010; Wu et al., 2010) was assessed using an MTT assay adapted from a previously described assay (Dahan et al., 2009; Kriedt et al., 2010). Cells were cultured and assayed at $37^{\circ} \mathrm{C}, 95 \%$ humidity, and $5 \% \mathrm{CO}_{2}$ in DMEM (SKBR3) or McCoy's 5A (SKOV3) medium, each supplemented with $10 \%$ FBS and penicillin/streptomycin. Cells $\left(3.13 \times 10^{4}\right.$ cells $\left./ \mathrm{cm}^{2}\right)$ were plated in 12-well plates (Griener BioOne) in complete media and incubated overnight. This plating regimen yielded $60 \%$ confluent cultures for testing. The cells were equilibrated in fresh media $(5 \mathrm{~h})$ and treated with $60 \mu \mathrm{M} \mathrm{MnTE}-2-\mathrm{PyP}^{5+}$ or its vehicle (saline), then with paclitaxel $(1,10,100,1000 \mathrm{~nm})$ or its vehicle ( $1 \%$ of $522 \mathrm{mg}$ of Cremophor in $43.2 \%$ ethanol). The cultures were incubated for $48 \mathrm{~h}$ and the level of cell survival was assessed by treating the cells with $500 \mu \mathrm{g} / \mathrm{ml} \mathrm{MTT}$ for $75 \mathrm{~min}, 37^{\circ} \mathrm{C}$. The medium was removed and the tetrazolium crystals were dissolved in isopropanol. The $A_{570 \mathrm{~nm}}$ was measured using a Genesys5 spectrophotometer (Thermo Fisher Scientific). $\%$ Survivability $=\left(A_{570 \mathrm{~nm}}\right.$ of the test well $) /\left(A_{570 \mathrm{~nm}}\right.$ veh $) \times 100$. The concentration providing $50 \%$ lethality $\left(\mathrm{LC}_{50}\right)$ for paclitaxel with or without $\mathrm{MnTE}-2-\mathrm{PyP}^{5+}$ was calculated using a three-parameter nonlinear analysis of $\%$ Survivability where the top and bottom plateaus were constrained using GraphPad Prism v5.03.

\section{Superoxide dismutase activity of PNDCs}

The SOD activity of PNDCs was determined by their competitive inhibition of luminal oxidation by xanthine/xanthine oxidase-derived superoxide (Bensinger and Johnson, 1981; Kimura and Nakano, 1988; Decraene et al., 2004). Serially diluted compounds were tested in duplicate by adding $50 \mu \mathrm{l}$ of compound/vehicle [ $4 \times$ in TE buffer: $50 \mathrm{~mm}$ Tris- $\mathrm{HCl}, \mathrm{pH} 7.8$, and $1 \mathrm{~mm}$ EDTA] and $50 \mu \mathrm{l}$ of xanthine oxidase from bovine milk, Grade III ( $0.4 \mathrm{U} / \mathrm{ml}$ in TE) to a 96-well white-walled microplate. A twofold serially diluted Cu,ZnSOD standard curve (0.25-260 $\mathrm{U} / \mathrm{ml}$ ) was similarly prepared. In a Glomax Multidection System (Model 9301, Promega) primed with xanthine (200 $\mu \mathrm{M}$ in TE buffer) and luminol (600 $\mu \mathrm{M}$ in TE), and xanthine (50 $\mu \mathrm{l})$ was automatically injected and read for $1 \mathrm{~s}$ following $1 \mathrm{~s}$ delay (background signal); then luminol $(50 \mu \mathrm{l})$ was injected and read for $1 \mathrm{~s}$ following $1 \mathrm{~s}$ delay (luminol signal). The final concentration of each component was compound/vehicle $(1 \times)$, xanthine oxidase $(0.1 \mathrm{U} / \mathrm{ml})$, luminol $(150 \mu \mathrm{M})$, and xanthine $(50 \mu \mathrm{M})$. The luminol signal was corrected for background signal and the SOD-like activity/ml of each compound was determined from the log-log linear regression analysis of $\mathrm{Cu}, \mathrm{ZnSOD}$ standard curve. The SOD activity per 
milligram (U/mg) of compound was measured as the slope of the $\mathrm{U} / \mathrm{ml}$ of serially diluted compound versus the concentration of compound ( $\mathrm{mg} /$ $\mathrm{ml}$ ). All linear analyses were performed using GraphPad Prism v5.03 with significance set at $p<0.05$.

Peroxynitrite decomposition via inhibition of aryl boronate oxidation assay

Stock solutions of 4-acetylphenylboronic acid and the catalyst were prepared in DMSO (in the 5-50 mM range). Peroxynitrite in $0.1 \mathrm{~N} \mathrm{NaOH}$ solution was prepared by the method of Pryor (Uppu et al., 1996) and frozen at $-80^{\circ} \mathrm{C}$ until needed. Small aliquots of the PN solution were thawed and kept on ice, and the concentration was measured by UV spectroscopy just before use. Peroxynitrite concentrations ranged from 58 to $77 \mathrm{~mm}$ for these studies. In a typical procedure, $9.5 \times 10^{-7} \mathrm{~mol}$ of 4 -acetylphenylboronic acid ( $24.0 \mu \mathrm{l}$ of stock) were dispensed into a small vial equipped with a magnetic stir bar. Phosphate buffer $(2.00 \mathrm{ml}, 100$ $\mathrm{mm}, \mathrm{pH}=7.2)$ containing $0.7 \%$ SDS and $100 \mu \mathrm{M}$ diethylenetriamine pentaacetic acid was added followed by $9.5 \times 10^{-7} \mathrm{~mol}$ of the catalyst (aliquot from DMSO stock). To this rapidly stirred mixture, PN (9.5 $\times$ $10^{-7} \mathrm{~mol}$ ) was rapidly injected. The mixture was stirred for $1 \mathrm{~min}$ and analyzed by liquid chromatography [Waters Alliance-MS3100 system; $15 \%$ acetonitrile/ $\mathrm{H}_{2} \mathrm{O}$ to $95 \%$ acetonitrile $(0.05 \%$ trifluoroacetic acid) over $10 \mathrm{~min}$; Agilent Eclipse XD8-C18 column, $5 \mu \mathrm{M}, 4.6 \times 150$ $\mathrm{mm}$, UV detection $280 \mathrm{~nm}$ for 4-hydroxyacetophenone oxidation product]. Replicate reactions $(n=5)$ were run and compared with controls (also $n=5$ ), which contained everything except the catalyst (amounts of DMSO that were equivalent to those from aliquoted catalyst solutions were added to the controls to compensate for the very small effect of DMSO). The peak areas for phenol oxidation products were compared for catalyst versus control runs to determine percentage inhibition.

Calculations:

$\%$ Inhibition $=\left(1-\frac{\mathrm{OX}_{\text {cat }}}{\mathrm{OX}_{\text {control }}}\right) \times 100\left(1-\frac{\mathrm{OX}_{\text {cat }}}{\mathrm{OX}_{\text {control }}}\right) \times 100$

$\% \mathrm{RSD}^{2}=\left(\% \mathrm{RSD} \mathrm{OX}_{\mathrm{cat}}\right)^{2}+\left(\% \mathrm{RSD} \mathrm{OX}_{\text {control }}\right)^{2}\left(\% \mathrm{RSD} \mathrm{OX}_{\mathrm{cat}}\right)^{2}$

$+\left(\% \text { RSD OX } \mathrm{OX}_{\text {control }}\right)^{2}$

$$
\begin{aligned}
\Delta \% I=\sqrt{\left(\frac{\Delta \mathrm{OX}_{\text {cat }}}{\mathrm{OX}_{\text {cat }}}\right)^{2} \times\left(\frac{\Delta \mathrm{OX}_{\text {control }}}{\mathrm{OX}_{\text {control }}}\right)^{2}} \\
\times \% \mathrm{I} \sqrt{\left(\frac{\Delta \mathrm{OX}_{\text {cat }}}{\mathrm{OX}_{\text {cat }}}\right)^{2} \times\left(\frac{\Delta \mathrm{OX}_{\text {control }}}{\mathrm{OX}_{\text {control }}}\right)^{2}} \times \% I
\end{aligned}
$$

Estimated $k$ for oxidation of $\mathrm{Mn}(\mathrm{III})$ to $\mathrm{Mn}(\mathrm{V})=\mathrm{O}$ :

$k_{\text {est }}=\left(\frac{\% \mathrm{I}}{100-\% \mathrm{I}}\right) \times 1.6 \times 10^{6} k_{\mathrm{est}}=\left(\frac{\% \mathrm{I}}{100-\% \mathrm{I}}\right) \times 1.6$

$\times 10^{6}$ (rate of oxidation of boronic acid by peroxynitrite)

$\% \mathrm{RSD}^{2}=(\% \mathrm{RSD} \text { OX })^{2}+\left(\% \mathrm{RSD} \mathrm{OX}_{\text {reduced }}\right)^{2}=(\% \mathrm{RSD} \mathrm{OX})^{2}$

$$
+\left(\% \mathrm{RSD} \mathrm{OX}_{\text {reduced }}\right)^{2}
$$

$$
\begin{aligned}
\Delta k_{\text {est }}=\sqrt{\left(\frac{\Delta \% \mathrm{I}}{\% \mathrm{I}}\right)^{2}}+\left(\frac{\Delta \% \mathrm{I}}{100-\% \mathrm{I}}\right)^{2} \\
\quad \times k_{\text {est }} \Delta k_{\text {est }}=\sqrt{\left(\frac{\Delta \% \mathrm{I}}{\% \mathrm{I}}\right)^{2}+\left(\frac{\Delta \% \mathrm{I}}{100-\% \mathrm{I}}\right)^{2}} \times k_{\text {est }}
\end{aligned}
$$

Statistical analysis

Data are expressed as mean \pm SD and analyzed with two-tailed, two-way repeated measures ANOVA with Bonferroni test or one-way ANOVA with Dunnett's test against paclitaxel group, where noted. Differences
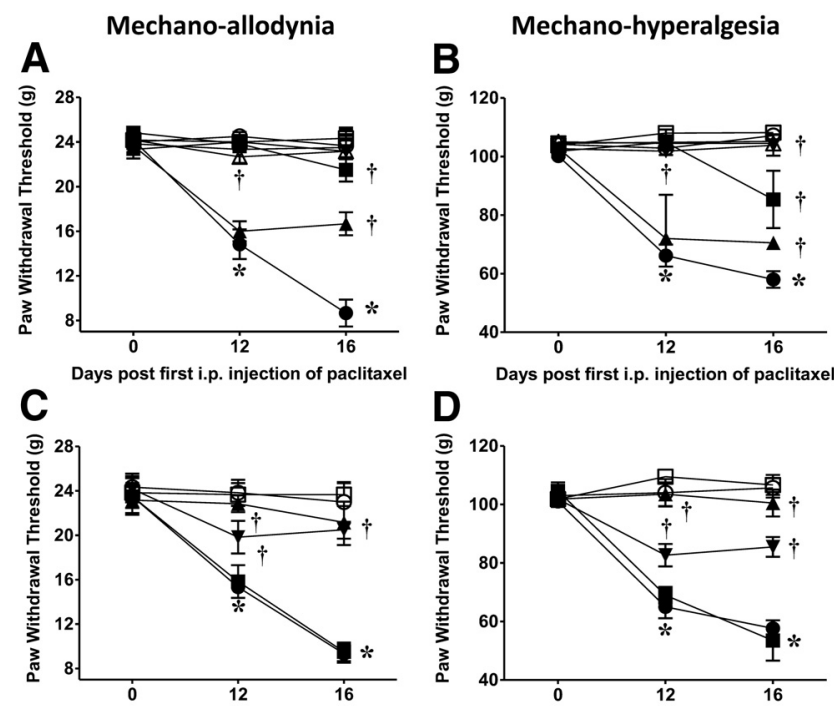

D

Days post first i.p. injection of paclitaxel
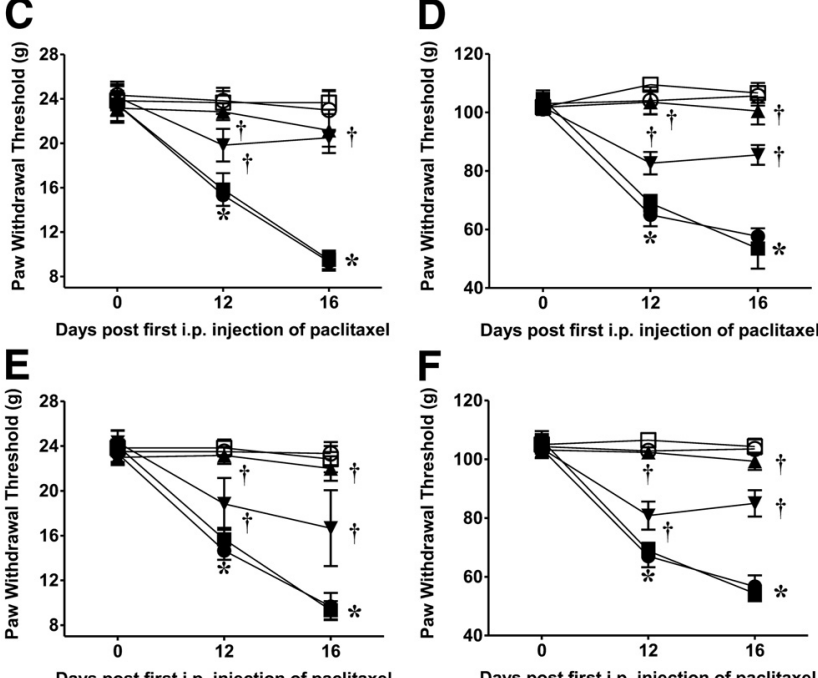

Days post first i.p. injection of paclitaxel

Figure 1. Targeting PN blocks neuropathic pain. $\boldsymbol{A}-\boldsymbol{F}$, Compared with vehicle $(\bigcirc)$, administration of paclitaxel (O) led to a time-dependent development of mechano-allodynia and mechanohyperalgesia that was attenuated by daily subcutaneous injections (D0-D15) of L-NAME (100 $\left.\mathrm{mg} \cdot \mathrm{kg}^{-1} \cdot \mathrm{d}^{-1} ; \boldsymbol{\square}, \boldsymbol{A}, \boldsymbol{B}\right), \mathrm{L}-\mathrm{NIL}\left(30 \mathrm{mg} \cdot \mathrm{kg}^{-1} \cdot \mathrm{d}^{-1}, \boldsymbol{\nabla}, \boldsymbol{A}, \boldsymbol{B}\right)$, apocynin $\left(100 \mathrm{mg} \cdot \mathrm{kg}^{-1} \cdot \mathrm{d}^{-1}\right.$, $\mathbf{\Delta}, \boldsymbol{A}, \boldsymbol{B})$, or FeTMPyP ${ }^{5+}(\boldsymbol{C}, \boldsymbol{D})$ and MnTE-2-PyP ${ }^{5+}(\boldsymbol{E}, \boldsymbol{F})$ at $1, \mathbf{\square} ; 3, \boldsymbol{\nabla} ;$ or $10 \mathrm{mg} \cdot \mathrm{kg}^{-1} \cdot \mathrm{d}^{-1}, \mathbf{\Delta}$. These drugs did not affect withdrawal thresholds in vehicle groups ( $A, B: L-N A M E, \square ; L-N I L, \nabla$; and apocynin, $\triangle ; \boldsymbol{C}, \mathbf{D}$ : FeTMPyP ${ }^{5+}, \square ; \boldsymbol{E}, \boldsymbol{F}$ :MnTE-2-PyP $\left.{ }^{5+}, \square\right)$. Results are expressed as mean \pm SD for 6 rats and analyzed by two-tailed, two-way repeated-measures ANOVA with Bonferroni comparisons. ${ }^{*} p<0.001$ for paditaxel versus vehicle and ${ }^{\dagger} p<0.001$ for paditaxel versus paclitaxel + experimental drugs.
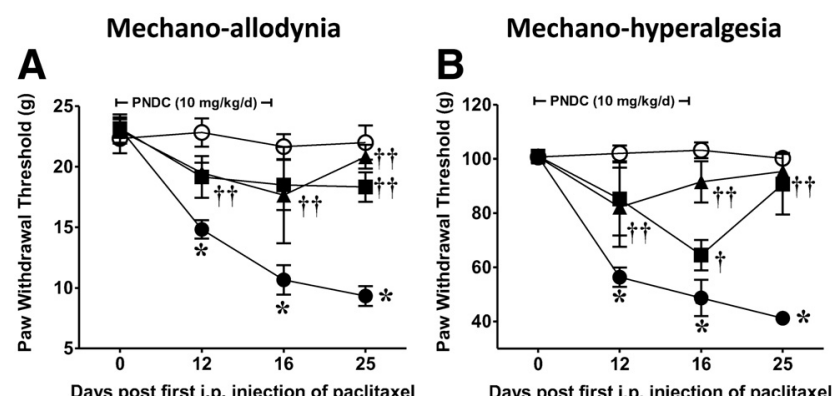

Figure 2. Neuropathic pain does not develop upon PNDC discontinuation. When compared with vehicle $(\bigcirc)$, administration of paclitaxel $(\bigcirc)$ led to a time-dependent development of mechanoallodynia $(\boldsymbol{A})$ and mechano-hyperalgesia $(\boldsymbol{B})$. These events were attenuated by daily subcutaneous injections (D0-D15) of FeTMPyP ${ }^{5+}(\boldsymbol{\square})$ and MnTE-2-PyP ${ }^{5+}(\mathbf{\Delta})$ at $10 \mathrm{mg} \cdot \mathrm{kg}^{-1} \cdot \mathrm{d}^{-1}$. Moreover, mechano-allodynia and mechano-hyperalgesia did not develop over an additional $10 \mathrm{~d}$ through D25 following discontinuation ofFeTMPyP ${ }^{5+}(\square)$ and MnTE-2-PyP ${ }^{5+}(\mathbf{\Delta})$. Results are expressed as mean \pm SD for 6 rats and analyzed by two-tailed, two-way repeated-measures ANOVA with Bonferroni comparisons. ${ }^{*} p<0.001$ for paditaxel versus vehicle and ${ }^{\dagger} p<0.01$ or ${ }^{\mathrm{t}} p<0.001$ for paclitaxel versus paditaxel + experimental drugs.

between dose-response curves for antitumor activity were analyzed by 3-parameter nonlinear analysis with constrained top and bottom plateaus and Hill Plot slopes. Dose-response curves for SOD activity were analyzed by linear regression analysis. Significance was accepted at $p<$ 
A
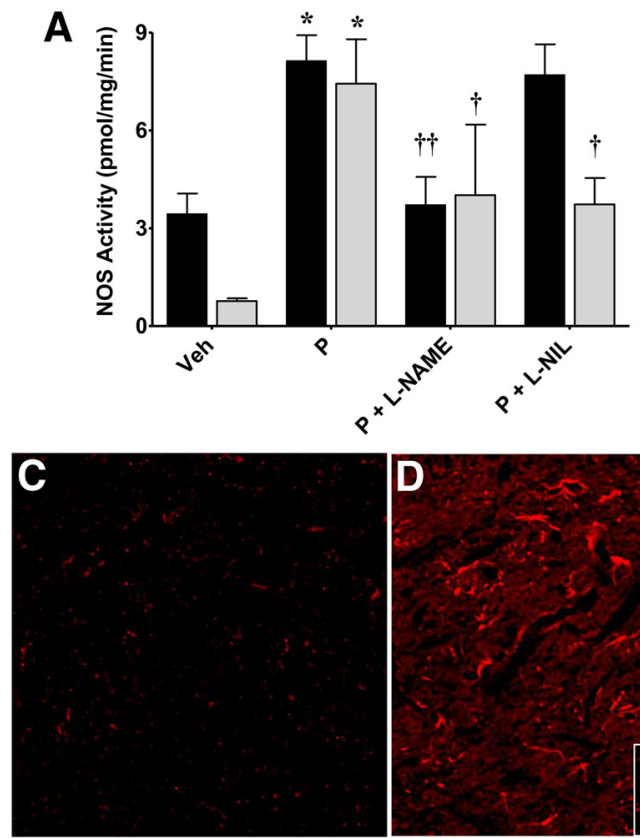

Veh

$\mathbf{P}$
B
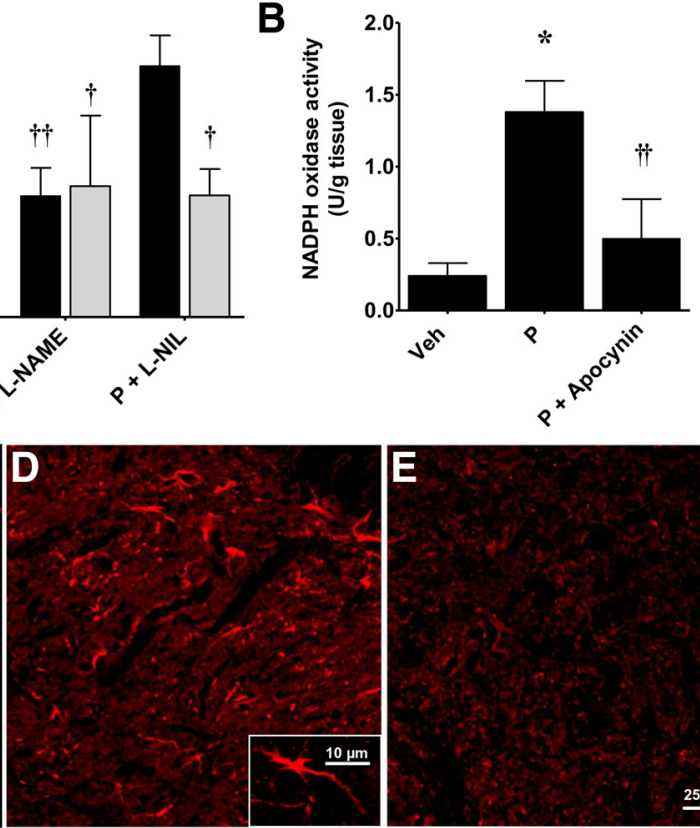

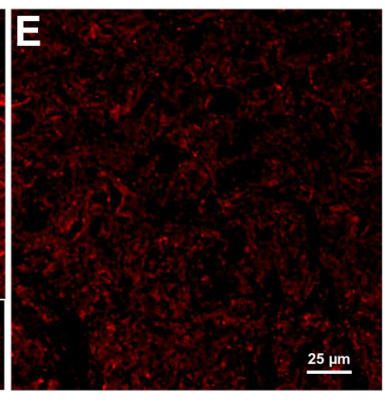

$\mathrm{P}+\mathrm{MnTE}-2-\mathrm{PyP}^{5+}$

Figure 3. Neuropathic pain increases nitric oxide synthase and NADPH oxidase activation and PN formation in the spinal dorsal horn. $\boldsymbol{A}-\boldsymbol{E}$, Compared with vehicle, paclitaxel increased the activity of constitutive/calcium-dependent NOS (black bars) and inducible/calcium-independent NOS (gray bars) $(\boldsymbol{A})$, and NADPH $(\boldsymbol{B})$. L-NAME $\left(100 \mathrm{mg} \cdot \mathrm{kg}^{-1} \cdot \mathrm{d}^{-1}\right)$ blocked constitutive/ calcium-dependent NOS ( $A$, black bars) activity, whereas L-NAME and L-NIL $\left(30 \mathrm{mg} \cdot \mathrm{kg}^{-1} \cdot \mathrm{d}^{-1}\right)$ inhibited inducible/calciumindependent NOS ( $\boldsymbol{A}$, gray bars) activity. Paclitaxel also increased NADPH oxidase activity, which was attenuated with apocynin $\left(100 \mathrm{mg} \cdot \mathrm{kg}^{-1} \cdot \mathrm{d}^{-1}, \boldsymbol{B}\right)$. As indicated by the formation of NT (red) in fixed frozen spinal cord sections $(\boldsymbol{C}-\boldsymbol{E})$, PN formation was low in dorsal horn from vehicle-treated animals $(\boldsymbol{C})$ but substantially increased with paclitaxel treatment $(\boldsymbol{D})$. This increase was attenuated by MnTE-2-PyP ${ }^{5+}\left(10 \mathrm{mg} \cdot \mathrm{kg}^{-1} \cdot \mathrm{d}^{-1} ; \boldsymbol{E}\right) . \boldsymbol{C}-\boldsymbol{E}$ are single-plane confocal images. The inset in $\boldsymbol{D}$ is a projected image of an 18 plane Z-stack to illustrate the morphology of a NT-positive cell in the volume of a $10 \mu \mathrm{m}$ dorsal horn section. Negative controls using normal rabbit serum for NT exhibited only low levels of background fluorescence. Micrographs are taken from superficial layers of dorsal horn of the spinal cord (lumbar enlargement) and are representative of at least 3 images from 3 different animals performed on different days. Enzymatic activities are mean \pm SD for 6 rats and analyzed by two-tailed, one-way ANOVA with Dunnett's comparisons to paclitaxel group. ${ }^{*} p<0.001$ for paclitaxel versus Veh; ${ }^{\dagger} p<0.01$ or ${ }^{{ }^{\dagger}} p<0.001$ for paclitaxel versus paclitaxel + experimental drugs.

0.05. All statistical analysis was performed using GraphPad Prism (Release 5.03).

\section{Results}

Targeting PN blocks the development of paclitaxel-induced neuropathic pain

Confirming previous reports (Polomano et al., 2001; Flatters and Bennett, 2006; Ledeboer et al., 2007), our experiments revealed that neuropathic pain (mechano-allodynia and mechano-hyperalgesia) was significant by D11-D12 (onset, Figs. 1,2), peaked by D16 (Figs. 1,2) and plateaued throughout our observation period (D25; Fig. 2). Although chemotherapy dosing is completed within a few days, we continued dosing until the time when the pain occurs. The delay to symptom onset (also noted in patients) introduces uncertainty about the time of onset of the relevant pathological process. Continuing treatment until D15 is thus prudent. When compared with the vehicle group, administration of paclitaxel led to the development of mechano-allodynia and mechano-hyperalgesia (Fig. 1) that was attenuated by daily administration of a nonselective NOS inhibitor, L-NAME $\left[100 \mathrm{mg} \cdot \mathrm{kg}^{-1} \cdot \mathrm{d}^{-1}\right.$, s.c., $n=6$; Fig. $1 A, B]$, a more iNOS-selective inhibitor $N^{6}$-(1iminoethyl)-L-lysine (L-NIL); $30 \mathrm{mg} \cdot \mathrm{kg}^{-1} \cdot \mathrm{d}^{-1}$, s.c., $n=6$; Fig. $\left.1 A, B\right]$ (Moncada et al., 1991), or by a well characterized NADPH oxidase inhibitor (apocynin, $100 \mathrm{mg} \cdot \mathrm{kg}^{-1} \cdot \mathrm{d}^{-1}$, s.c., $n=6$; Fig. $1 A, B$ ) (Simons et al., 1990). When given alone, L-NAME, L-NIL or apocynin did not affect baseline withdrawal thresholds (Fig. $1 A, B$ ). Since NO is known to react with $\mathrm{SO}$ at a near diffusion-limited rate to form PN (Beckman et al., 1990), these results indirectly suggest that PN generated from these species is the common denominator leading to neuropathic pain. The role of $\mathrm{PN}$ in CIPN was established using the well characterized iron and mangano porphyrin-based PNDCs, FeTMPyP ${ }^{5+}$ and MnTE-2-PyP ${ }^{5+}$ (Salvemini et al., 1998; Batinic-Haberle et al., 2010). Thus, subcutaneous injections of FeT$\mathrm{MPyP}^{5+}$ or MnTE-2-PyP ${ }^{5+}$ attenuated the development of neuropathic pain in a dosedependent manner $\left(1-10 \mathrm{mg} \cdot \mathrm{kg}^{-1}\right.$. $\mathrm{d}^{-1}, n=6$; Fig. $1 C, D$; $E, F$, respectively). The $\mathrm{ED}_{50}$ (effective dose providing $50 \%$ effect) of FeTMPyP $^{5+}$, as calculated on D16 for mechano-allodynia and mechano-hyperalgesia, was 2.2 and $2.8 \mathrm{mg} \cdot \mathrm{kg}^{-1} \cdot \mathrm{d}^{-1}$ and that for MnTE-2-PyP ${ }^{5+}$ was 3.1 and 2.7 $\mathrm{mg} \cdot \mathrm{kg}^{-1} \cdot \mathrm{d}^{-1}$. When given alone, and at the highest dose tested $\left(10 \mathrm{mg} \cdot \mathrm{kg}^{-1} \cdot \mathrm{d}^{-1}, n=\right.$ 6), FeTMPyP ${ }^{5+}$ (Fig. 1C,D) or MnTE-2$\mathrm{PyP}^{5+}$ (Fig. 1E,F) did not affect baseline withdrawal thresholds. To determine whether $\mathrm{CIPN}$, once it is prevented from developing, emerges after discontinuation of the drug, rats were treated for a period of $15 \mathrm{~d}$ with FeT$\mathrm{MPyP}^{5+}$ or MnTE-2-PyP ${ }^{5+}\left(10 \mathrm{mg} \cdot \mathrm{kg}^{-1}\right.$. $\left.\mathrm{d}^{-1}, n=6\right)$ and mechano-allodynia and hyperalgesia subsequently evaluated for an additional $10 \mathrm{~d}$ through D25. As can be seen in Figure 2, when treatment with FeTMPyP ${ }^{5+}$ or MnTE-2-PyP ${ }^{5+}$ was discontinued on D15 neuropathic pain did not emerge. Paclitaxel-induced neuropathic pain is
associated with activation of nitric
oxide synthases and NADPH oxidase in
spinal cord
vehicle $(n=6)$, the development of neu When compared with vehicle $(n=6)$, the development of neu-
ropathic pain at the time of peak (D16) was associated with increased activation of the calcium-dependent/constitutive and -independent/inducible NOS activity (Fig. 3A). L-NAME (100 $\left.\mathrm{mg} \cdot \mathrm{kg}^{-1} \cdot \mathrm{d}^{-1}, n=6\right)$, but not L-NIL $\left(30 \mathrm{mg} \cdot \mathrm{kg}^{-1} \cdot \mathrm{d}^{-1}, n=\right.$ 6), blocked constitutive NOS, whereas both inhibited inducible NOS (Fig. 3A), as expected. Significantly increased activation of NADPH oxidase and SO production in spinal cord was also observed and this was blocked by apocynin $\left(100 \mathrm{mg} \cdot \mathrm{kg}^{-1} \cdot \mathrm{d}^{-1}\right.$, $n=5$, Fig. $3 B$ ).

\section{Peroxynitrite formation and post-translational tyrosine} nitration of mitochondrial superoxide dismutase, glutamate transporters and glutamine synthetase

Activation of NOS and NADPH oxidase are important in the biosynthesis of $\mathrm{PN}$ as they provide its precursors, $\mathrm{NO}$ and $\mathrm{SO}$ (Beckman et al., 1990). The highly reactive nature of $\mathrm{PN}$, its formation, and its decomposition prevents direct measurements of $\mathrm{PN}$ in vivo and therefore, the detection of the formation of 3-nitrotyrosine (NT), is widely used for as a "footprint marker" to verify its presence provided that its expression is prevented by PNDCs (Szabó et al., 2007). As can be seen in Figure 3, when compared with the vehicle group (Fig. $3 C$ ), the formation of NT increased in the dorsal horn of paclitaxel-treated animals 
(Fig. 3D) and this was attenuated in rats treated with MnTE-2-PyP ${ }^{5+}$ (10 $\mathrm{mg} \cdot \mathrm{kg}^{-1} \cdot \mathrm{d}^{-1}, n=3$, s.c., Fig. 3E). Once formed, $\mathrm{PN}$ nitrates and inactivates mitochondrial MnSOD, the key enzyme keeping SO and thus $\mathrm{PN}$ in check (McCord and Fridovich, 1969). $\mathrm{PN}$-mediated nitration and inactivation of MnSOD is an additional significant source in maintaining elevated levels of $\mathrm{PN}$ at pathophysiological sites (Macmillan-Crow and Cruthirds, 2001). The occurrence of this nitrated MnSOD in the spinal cord has been also linked to development of central sensitization in several experimental models of pain (for review, see Salvemini et al., 2011). We now show that this process is operative in paclitaxel-induced neuropathic pain as shown in Figure 4. Significant nitration of MnSOD was observed in spinal cord of paclitaxel rats (Fig. $4 A$ ) and this was associated with a significant loss in its ability to enzymatically dismutate $\mathrm{SO}$ (Fig. 4B). MnTE-2-PyP ${ }^{5+}$ (10 $\mathrm{mg} \cdot \mathrm{kg}^{-1} \cdot \mathrm{d}^{-1}, n=6$, s.c.) prevented MnSOD nitration (Fig. $4 A$ ) and its inactivation (Fig. $4 B$ ). The enzymatic activity of cytosolic $\mathrm{Cu}, \mathrm{ZnSOD}$ remained unaffected (Table 1). Furthermore, we found that two proteins normally restricted to astrocytes and responsible for regulating glutamatergic signaling were nitrated in spinal cords from paclitaxel-treated rats, namely GLT-1 (Fig. 4C, $n=6$ ) and GS (Fig. $4 D, n=6$ ). Such post-translational nitration and modification was blocked in rats treated with MnTE-2-PyP ${ }^{5+}\left(10 \mathrm{mg} \cdot \mathrm{kg}^{-1} \cdot \mathrm{d}^{-1}, n=6\right.$; Fig. 4C,D).

The development of neuropathic pain is associated with increased PN-sensitive glial expression of GFAP and OX-42 in spinal cord

When compared with the vehicle group, the development of neuropathic pain was associated with enhanced expression of the astrocyte-associated GFAP and microglia associated OX-42 expression (Fig. $5 A, B, n=4)$. MnTE-2-PyP ${ }^{5+}\left(10 \mathrm{mg} \cdot \mathrm{kg}^{-1} \cdot \mathrm{d}^{-1}\right)$ significantly reduced GFAP and OX-42 protein expression (Fig. $5 A, B$, $n=4)$.

PN contributes to the development of neuropathic pain through modulation of pro- and anti-inflammatory cytokines in spinal cord

When compared with the vehicle group, the development of neuropathic pain was associated with enhanced formation of TNF- $\alpha$ and IL- $1 \beta$ (Fig. $5 C, D, n=4$ ) and a small, but significant, increase in IL-10 and IL-4 (Fig. $5 E, F, n=5)$. MnTE-2-PyP ${ }^{5+}(10$ $\mathrm{mg} \cdot \mathrm{kg}^{-1} \cdot \mathrm{d}^{-1}$ ) significantly reduced TNF- $\alpha$ and IL-1 $\beta$ (Fig. $5 C, D, n=4)$, whereas it significantly increased the levels of IL-10 and IL-4 (Fig. $5 E, F, n=5$ ).

Intrathecal delivery of MnTE-2-PyP ${ }^{5+}$ blocks the development of neuropathic pain

Intrathecal delivery of FeTMPyP ${ }^{5+}(0.1-1 \mathrm{nmol} / \mathrm{d}, n=6$; Fig. $6 A, B)$ or MnTE-2-PyP ${ }^{5+}(0.1-1 \mathrm{nmol} / \mathrm{d}, n=6$; Fig. $6 C, D)$ at-
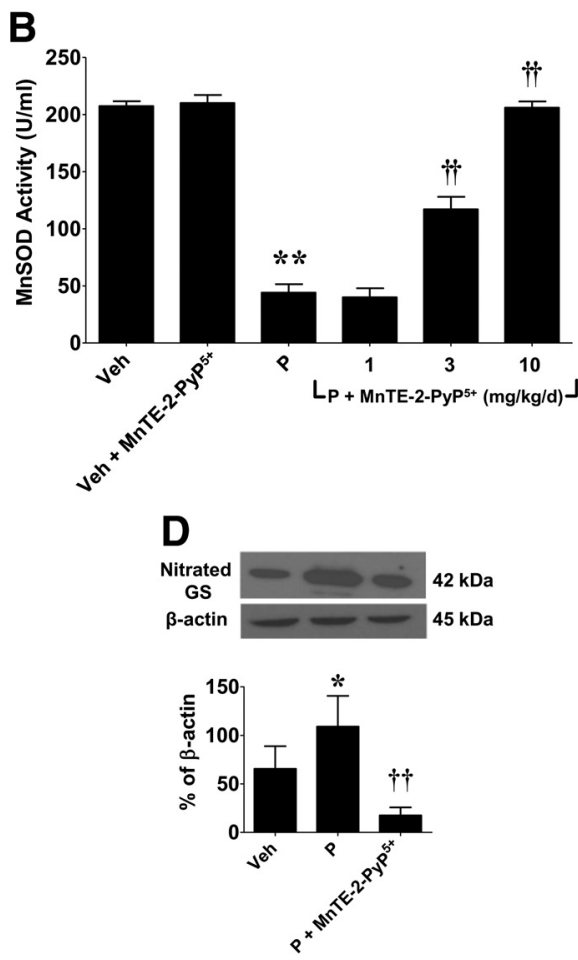

Figure 4. Attenuation of post-translational nitration of MnSOD, GLT-1, and GS by MnTE-2-PyP ${ }^{5+}$. $\boldsymbol{A}-\boldsymbol{D}$, Compared with vehicle, paclitaxel led to post-translational nitration $(\boldsymbol{A})$ and enzymatic inactivation of mitochondrial $\mathrm{MnSOD}(\boldsymbol{B})$, events blocked by (10 $\left.\mathrm{mg}^{\mathrm{kg}}{ }^{-1} \cdot \mathrm{d}^{-1}\right)$. Moreover, compared with vehicle, pacliwith MnTE-2-PyP $\mathrm{P}^{5+}\left(10 \mathrm{mg} \cdot \mathrm{kg}^{-1} \cdot \mathrm{d}^{-1} ; \boldsymbol{C}, \boldsymbol{D}\right)$. Results are expressed as mean \pm SD for 6 rats and analyzed by two-tailed, one-way ANOVA with Dunnett's comparisons to paclitaxel group. ${ }^{*} p<0.05$ or ${ }^{* *} p<0.001$ for paclitaxel versus Veh; ${ }^{\dagger} p<0.01$ or ${ }^{\dagger \dagger} p<0.001$ for paclitaxel versus paclitaxel + MnTE-2-PyP ${ }^{5+}$.

\section{Table 1. Cu,ZnSOD activity}

\begin{tabular}{ll}
\hline & \\
\hline Veh & Cu,ZnSOD Activity $(\mathrm{U} / \mathrm{ml})$ \\
$P$ & $209 \pm 7.4$ \\
$\mathrm{P}+\mathrm{MnTE}-2-P y P^{5+}$ & $206 \pm 5.5$ \\
$\quad 1 \mathrm{mg} \cdot \mathrm{kg}^{-1} \cdot \mathrm{d}^{-1}$ & \\
$\quad 3 \mathrm{mg} \cdot \mathrm{kg}^{-1} \cdot \mathrm{d}^{-1}$ & $208 \pm 8.7$ \\
$\quad 10 \mathrm{mg} \cdot \mathrm{kg}^{-1} \cdot \mathrm{d}^{-1}$ & $207 \pm 7.0$ \\
Veh $+\mathrm{MnTE}-2-\mathrm{PyP}^{5+}\left(10 \mathrm{mg} \cdot \mathrm{kg}^{-1} \cdot \mathrm{d}^{-1}\right)$ & $200 \pm 7.1$ \\
\hline
\end{tabular}

Mean \pm SD for $n=6$ rats.

tenuated the development of mechano-allodynia and mechanohyperalgesia in a dose-dependent fashion. In addition, injections of MnTE-2-PyP ${ }^{5+}(1 \mathrm{nmol} / \mathrm{d}, n=6)$ blocked the increased formation of TNF- $\alpha$ and IL- $\beta$ (Fig. $6 E, F, n=6$ ), but increased the formation of IL-10 and IL-4 (Fig. $6 G, H, n=6$ ).

Systemic or intrathecal delivery of FeTMPyP ${ }^{5+}$ or MnTE-2$\mathrm{PyP}^{5+}$ reverse paclitaxel-induced neuropathic pain

To test whether the removal of $\mathrm{PN}$ reverses neuropathic pain once established, FeTMPyP ${ }^{5+}$ or MnTE-2-PyP ${ }^{5+}$ (or their vehicle, saline) was given intraperitoneally $(10 \mathrm{mg} / \mathrm{kg}, n=6$, Fig. $7 A, B)$ or intrathecally $(1 \mathrm{nmol} / \mathrm{kg}, n=6$, Fig. $7 C, D)$ on D16. FeTMPyP ${ }^{5+}$ and MnTE-2-PyP ${ }^{5+}$ rapidly (within $30 \mathrm{~min}$ ) and completely reversed mechano-allodynia and hyperalgesia which lasted at least for $5 \mathrm{~h}$ (Fig. 7); these effects were lost at the $24 \mathrm{~h}$ time point (data not shown). Doses of FeTMPyP ${ }^{5+}$ or MnTE-2$\mathrm{PyP}^{5+}$ were chosen from pilot dose-ranging experiments and used at a dose found to cause near-to-maximal reversal. 

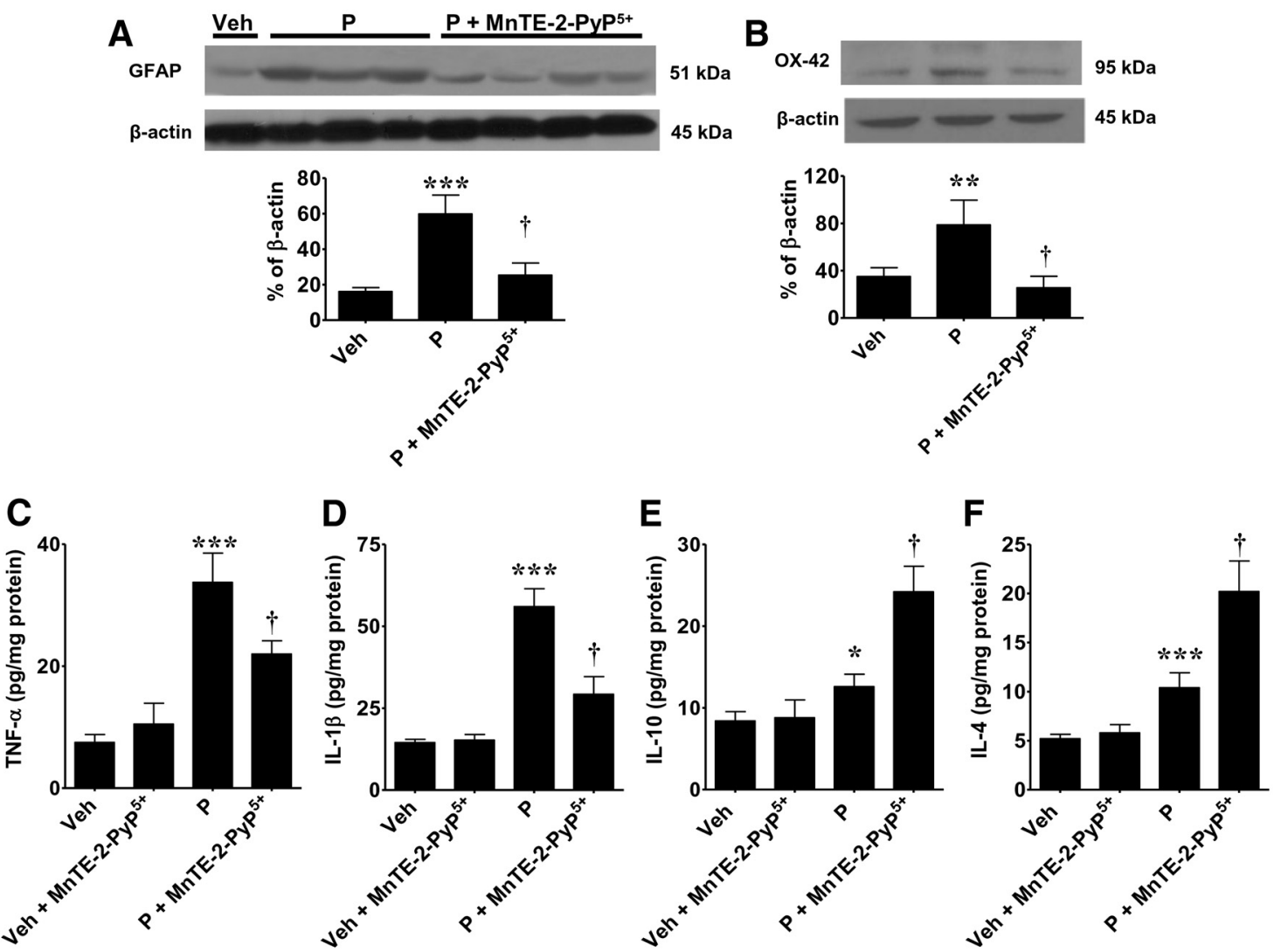

Figure 5. MnTE-2-PyP ${ }^{5+}$ attenuates GFAP, $O X-42$, and pro-inflammatory cytokine expression and favors anti-inflammatory cytokine production. $A-D$, Compared with vehicle (Veh), paclitaxel $(P)$ increased GFAP $(\boldsymbol{A}), 0 \mathrm{XX}-42(\boldsymbol{B})$, TNF- $\alpha(\boldsymbol{C})$, and IL-1 $\beta(\boldsymbol{D})$ expression $(n=4)$, which was significantly attenuated by MnTE-2-PyP ${ }^{5+}\left(10 \mathrm{mg} \cdot \mathrm{kg}^{-1} \cdot \mathrm{d}^{-1}, \mathrm{i} . \mathrm{p}.\right)$. $\boldsymbol{E}, \boldsymbol{F}, \mathrm{Compared}$ with Veh, paclitaxel $(P)$ increased anti-inflammatory IL-10 and IL-4 $(\boldsymbol{E}, F, n=5)$ and was substantially enhanced by MnTE-2-PyP ${ }^{5+}\left(10 \mathrm{mg} \cdot \mathrm{kg}^{-1} \cdot \mathrm{d}^{-1}\right.$, i.p.). Results are expressed as mean \pm SD for $(n)$ rats and analyzed by two-tailed, one-way ANOVA with Dunnett's comparisons to paclitaxel group. ${ }^{*} p<0.05$, ${ }^{* *} p<0.01$, or ${ }^{* * *} p<0.001$ for paclitaxel versus Veh; ${ }^{\dagger} p<0.001$ for paclitaxel versus paclitaxel + MnTE-2-PyP ${ }^{5+}$.

\begin{abstract}
MnTE-2-PyP ${ }^{5+}$ does not interfere with the antitumor effects of paclitaxel

MnTE-2-PyP ${ }^{5+}$ was chosen as a prototype agent since it catalytically decomposes both $\mathrm{SO}$ and PN (with preference toward PN in biological compartments in which both $\mathrm{SO}$ and $\mathrm{NO}$ are generated) and importantly because we had pharmacokinetic information to guide appropriate dose selection (Spasojević et al., 2008). In rats following a systemic injection of MnTE-2-PyP ${ }^{5+}$ at a dose providing near-to-maximal inhibition of neuropathic pain (10 mg/kg), plasma levels at $C_{\max }$ were $17 \mu \mathrm{M}$ (Spasojević et al., 2008). Using a concentration 3 times higher than $C_{\max }(60 \mu \mathrm{M})$, the effect of MnTE-2-PyP ${ }^{5+}$ on the antitumor effects of paclitaxel was measured by the MTT assay (Shah et al., 2009; Kriedt et al., 2010) in the well characterized human breast (SKBR3) (Itamochi et al., 2011) and ovarian (SKOV3) (Lacroix and Leclercq, 2004; Wu et al., 2010) cancer cells. The antitumor activity of paclitaxel in SKBR3 $\left(\mathrm{LC}_{50}=9.6 \mathrm{nM}\right)$ and SKOV3 $\left(\mathrm{LC}_{50}=14.0\right.$ nM) cells was not hindered, but if anything, enhanced by MnTE$2-\mathrm{PyP}^{5+}\left(\mathrm{LC}_{50}=4.2 \mathrm{~nm} ; p<0.05\right.$ and $5.7 \mathrm{~nm} p<0.001$ in SKBR3 and SKOV 3 cells, respectively; $n=4)$.
\end{abstract}

SRI6 and SRI110 are novel orally active "SO-sparing" PNDCs To test feasibility of engineering "SO-sparing PNDCs" with properties inherent of oral bioavailability, we selected a chemical design paradigm for which PN decomposition selectivity (over $\mathrm{SO}$ ) and drug properties run in parallel. Our efforts to identify such a catalyst led to the discovery of two PNDCs of distinct classes: our previously reported SRI110 (Rausaria et al., 2011a) and SRI6 (Rausaria et al., 2011b) (Fig. 8A). SRI110 is a neutral $\mathrm{Mn}(\mathrm{III})$ complex from the novel bis-hydroxyphenyldipyrromethene class and SRI6 is an electron rich $\mathrm{Mn}$ (III) porphyrin system. To measure (under varying conditions) the PN decomposition activity of complexes designed to be membrane soluble, we developed an in vitro assay based upon the inhibition of aryl boronate oxidation by PN (Sikora et al., 2009). As can be seen from Figure $8 B$, stochiometric SRI6 shows $30.8 \pm 2.3 \%$ inhibition of the oxidation of 4-acetylphenylboronic acid by PN at $25^{\circ} \mathrm{C}$. This corresponds to an apparent estimated second order rate constant of $7.1 \pm 0.5 \times 10^{5} \mathrm{M}^{-1} \mathrm{~s}^{-1}$ for the oxidation of SRI6 to the corresponding oxoMn(IV) species with the concomitant 1-electron reduction of PN. Ebselen (Sies and Masumoto, 1997) and Mn-4-TMPyP ${ }^{5+}$ (Ferrer-Sueta and Radi, 2009) were used as controls since their second order rate constants with PN are well known (Fig. $8 \mathrm{~B}$ ). The estimated second order rate constants for each of these compounds as determined by this assay match well with these published values (Fig. $8 \mathrm{~B}$ ). The rapid in vivo reduction of the resultant oxoMn(IV) form of SRI6 by endogenous antioxidants (ascorbate, glutathione, etc.) should complete a reductasetype catalytic cycle (Ferrer-Sueta and Radi, 2009). Similar values were found with the 2-electron PNDC, SRI110 (this complex is oxidized to the oxoMn $(\mathrm{V})$ species with concomitant 2-electron reduction of PN). The carefully chosen chemical design features of SRI6 or SRI110 (Rausaria et al., 2011a) give it membrane solubility and reduce its activity toward SO by adjustment of the redox potential of the metal center. Importantly and as previously shown with SRI110, SRI6 behaves as a "SO-sparing 


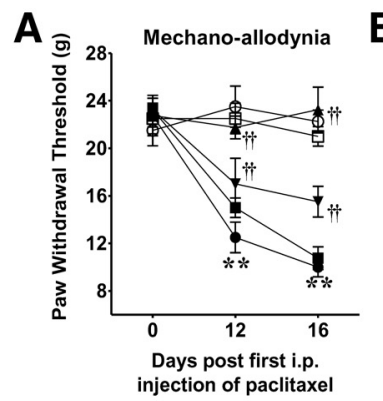

E

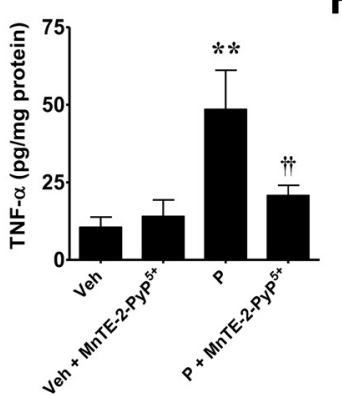

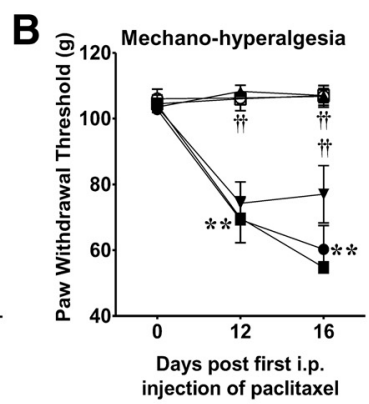

$\mathbf{F}$

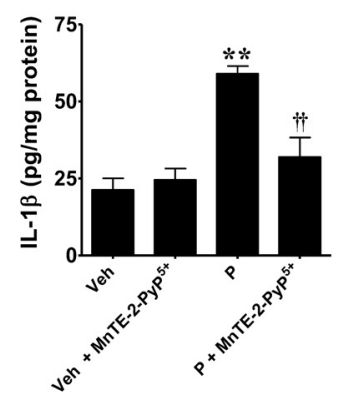

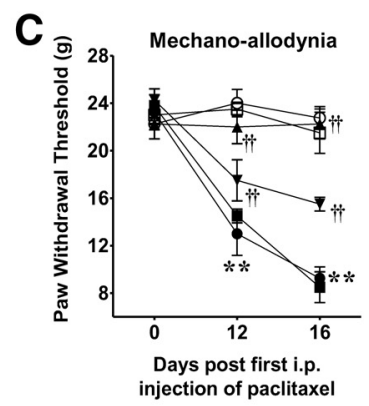

G

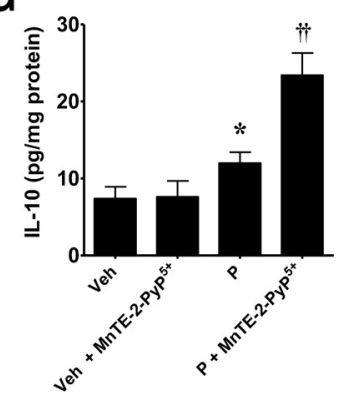

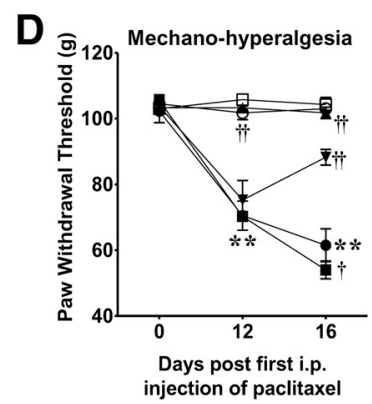

H

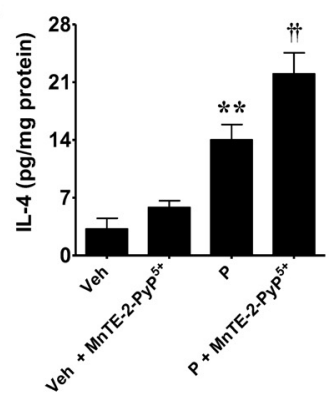

Figure 6. Intrathecal (i.th.) delivery of SODm/PNDCs blocks the development of neuropathic pain and modulates spinal cytokine production. $A-D, C$ mpared with vehicle (Veh, $\bigcirc)$, paclitaxel (P, - led to a time-dependent development of mechano-allodynia $(\boldsymbol{A}, \boldsymbol{C})$ and mechano-hyperalgesia $(\boldsymbol{B}, \boldsymbol{D})$ that was attenuated by daily i.th. delivery of FeTMPyP $\mathrm{P}^{5+}(\boldsymbol{A}, \boldsymbol{B})$ or MnTE-2-PyP $\mathrm{P}^{5+}(\boldsymbol{C}, \boldsymbol{D})$ at $0.1, \mathbf{\square} ; 0.3, \boldsymbol{\nabla}$; and $1 \mathrm{nmol} / \mathrm{d}, \boldsymbol{\Delta})$. These drugs did not affect withdrawal thresholds in vehicle groups $(\square, \boldsymbol{A}-\boldsymbol{D}) . \boldsymbol{E}, \boldsymbol{F}$, Compared with vehicle group, paclitaxel increased TNF- $\alpha$ and $I L-1 \beta(\boldsymbol{E}, \boldsymbol{F})$ and this was inhibited by MnTE-2-PyP ${ }^{5+}\left(10 \mathrm{mg} \cdot \mathrm{kg}^{-1} \cdot \mathrm{d}^{-1}\right.$, i.th.). $\mathbf{G}, \boldsymbol{H}$, Paclitaxel led to a modest increase in IL-10 and IL-4 (G, $\left.\boldsymbol{H}\right)$ production compared with vehicle; but was substantially enhanced with daily i.th. delivery of MnTE-2-PyP $\mathrm{P}^{5+}\left(10 \mathrm{mg} \cdot \mathrm{kg}^{-1} \cdot \mathrm{d}^{-1}\right)$. Results are expressed as mean \pm SD for 6 rats. Behavioral data were analyzed by two-tailed, two-way repeatedmeasures ANOVA with Bonferroni comparisons. Data for cytokine production were analyzed by two-tailed, one-way ANOVA with Bonferroni comparisons to paclitaxel group. ${ }^{*} p<0.01$ or ${ }^{* *} p<$ 0.001 for paclitaxel versus vehicle; ${ }^{\dagger} p<0.01$ or ${ }^{\dagger+} p<0.001$ for paclitaxel versus paclitaxel + MnTE-2-PyP ${ }^{5+}$.

PNDC". Indeed, the SOD activities of SRI6 and SRI110 were negligible compared with FeTMPyP ${ }^{5+}$ as determined by their capacity to inhibit luminol oxidation by xanthine/xanthine oxidase-derived superoxide (Fig. 8C).

Oral delivery of SO-sparing PNDCs blocks the development of paclitaxel-induced neuropathic pain

Oral administration of SRI6 (Fig. 9A,B) and SRI110 (Fig. 9C,D) at $30 \mathrm{mg} \cdot \mathrm{kg}^{-1} \cdot \mathrm{d}^{-1}$ for $15 \mathrm{~d}(n=5)$ blocked the development of paclitaxel-induced neuropathic pain. Beneficial effects were associated with decrease formation of TNF- $\alpha$ and IL- $1 \beta$ (Fig. 9E, F) and increased formation of IL-10 and IL-4 (Fig. $9 G, H$ ) in spinal cord. Doses of SRI6 and SRI110 were chosen from pilot doseranging experiments and used at a dose found to cause near-tomaximal reversal.

\section{Discussion}

Using a well characterized rat model of paclitaxel-induced neuropathic pain resembling the peripheral neuropathies in patients (Polomano et al., 2001), our results reveal that overt production of PN is a critical determinant of pain. Inhibition of PN formation not only blocked the development of neuropathic pain, but also reversed it. Remarkably, after discontinuing FeTMPyP ${ }^{5+}$ and MnTE-2-PyP ${ }^{5+}$, mechano-allodynia and mechano-hyperalgesia did not reemerge, suggesting a possibility for long-term prevention of pain and substantial benefit to patients undergoing chemotherapy. Neuropathological changes in the spinal cord via neuroinflammation (Ledeboer et al., 2006; Peters et al., 2007; Zhang et al., 2012) and altered glutamatergic signaling (Weng et al., 2005; Cata et al., 2006a; Zhang et al., 2012) have been reported to underlie the development of paclitaxel-induced neuropathic pain. The triggering events are not well understood, but our re- sults support PN formation in spinal cord as one potential mechanism. To this end, neuropathic pain was associated with increased NT formation in the dorsal horn, which was blocked by MnTE-2- $\mathrm{PyP}^{5+}$. The functional role of $\mathrm{PN}$ at spinal sites was strengthened by the findings that intrathecal delivery of the PNDCs blocked the development of paclitaxel-induced neuropathic pain. Although these findings implicate spinal PN, we cannot exclude the effects on the dorsal root ganglion due to drug exposure to intrathecal injections (Ledeboer et al., 2007). Enzymatic sources identified in $\mathrm{PN}$ formation included activation of NOS isoforms and NADPH oxidase; whose products, NO and $\mathrm{SO}$, provide the precursors for the biosynthesis of PN (Beckman et al., 1990). An additional source was nitration of MnSOD, which disrupts its enzymatic activity providing a "feedforward" mechanism sustaining elevated PN through elevated SO (Macmillan-Crow and Cruthirds, 2001). The fact that Cu,ZnSOD activity was unaffected is consistent with the fact that PN does not affect the catalytic activity of Cu,ZnSOD (Smith et al., 1992). Viable sources for PN production include neurons and/or activated glia, since both generate NO and SO (for review, see Salvemini et al., 2011). Pinpointing the cell population(s) in vivo responsible for $\mathrm{PN}$ production is difficult given the membrane diffusability of PN to allow post-translational nitration in adjacent cells (Ferrer-Sueta and Radi, 2009). The site(s) of PN action becomes important to understanding the underlying mechanisms, particularly in glia (i.e., astrocytes and/or microglia), which through increased formation of pro- and anti-inflammatory cytokines (for review, see Watkins et al., 2001; Milligan and Watkins, 2009) and maintenance of synaptic glutamate homeostasis (Kugler, 1993) play a role in central sensitization associated with neuropathic pain states. The contribution of as- 


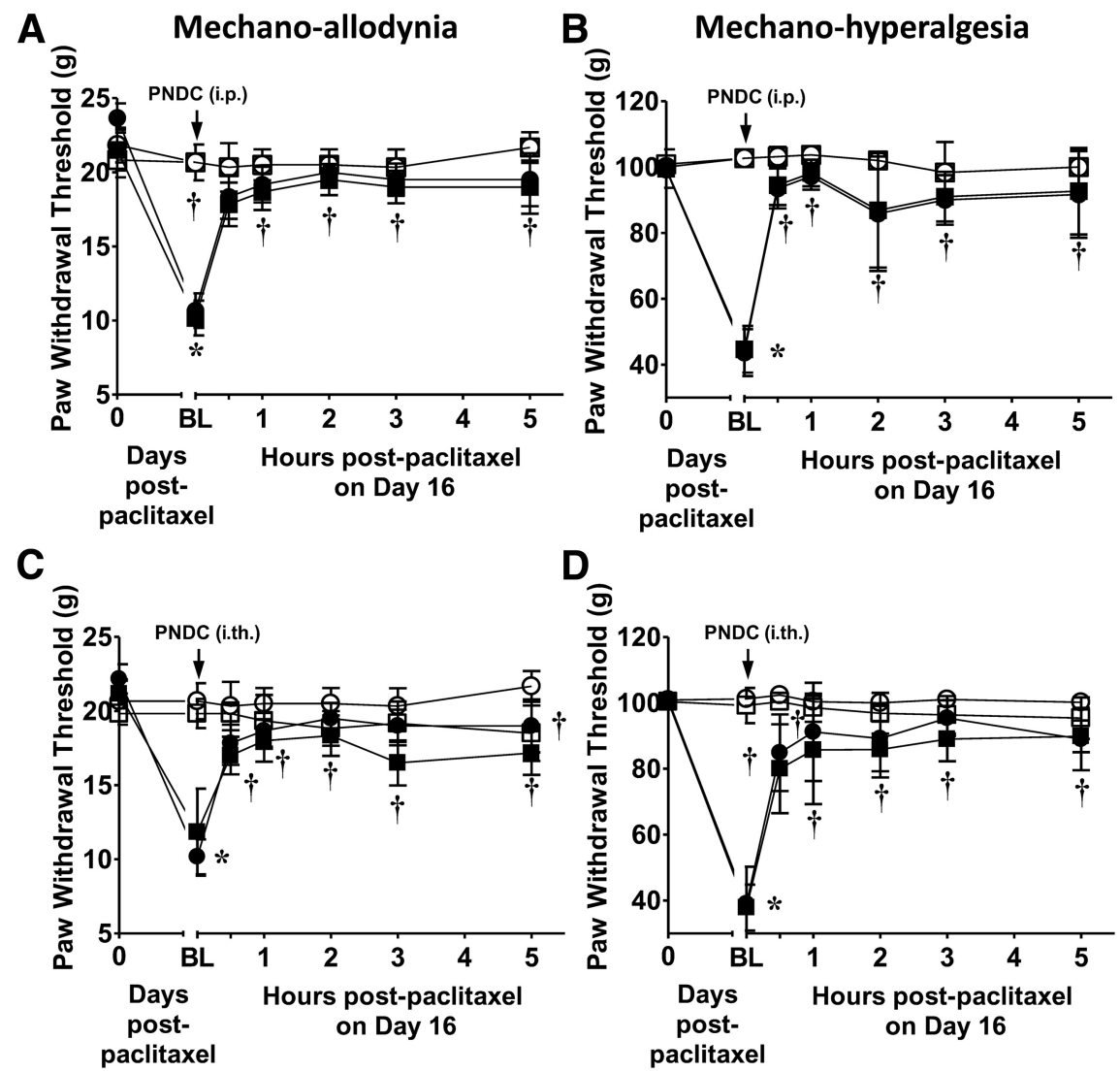

Figure 7. Systemic or intrathecal delivery of FeTMPyP ${ }^{5+}$ or MnTE-2-PyP ${ }^{5+}$ reverse established paclitaxel-induced neuropathic pain. $\boldsymbol{A}-\boldsymbol{D}$, Intraperitoneal $(\boldsymbol{A}, \boldsymbol{B} ; 10 \mathrm{mg} / \mathrm{kg})$ or intrathecal $(\boldsymbol{C}, \boldsymbol{D} ; 1 \mathrm{nmol} / \mathrm{kg})$ administration of FeTMPyP ${ }^{5+}(\boldsymbol{O})$ or MnTE2-PyP ${ }^{5+}(\square)$ on D16 rapidly reversed mechano-allodynia and mechano-hyperalgesia. FeTMPyP ${ }^{5+}(\bigcirc)$ or MnTE-2-PyP ${ }^{5+}(\square)$ did not affect baseline mechano-allodynia $(\boldsymbol{A}, \boldsymbol{C})$ and mechano-hyperalgesia $(\boldsymbol{B}, \boldsymbol{D})$ values. Results are mean $\pm S D$ for $n=6$ rats and were analyzed by two-tailed, two-way repeated-measures ANOVA with Bonferroni comparisons to treatment-matched DO or baseline values. ${ }^{*} p<0.001$ for baseline versus $\mathrm{D} 0 ;{ }^{\dagger} p<0.001$ behavior at $t$ versus treatment-matched baseline values.

production. It is possible that reducing $\mathrm{SO}$ levels through preserved endogenous MnSOD activity by removing PN or directly dismutating SO, MnTE-2-PyP ${ }^{5+}$ supports NO levels beneficial to IL-10 and IL-4 production. Second, PN regulates proteins necessary for glutamatergic homeostasis. To this end, we found that the development of neuropathic pain was associated with nitration of the glia-derived GLT-1 and GS in spinal cord, a process blocked by MnTE-2-PyP ${ }^{5+}$. GLT-1 together with GLAST, another GT largely found in astrocytes, account for $>80 \%$ of glutamate reuptake and control the termination of glutamatergic signaling at these sites (Kugler, 1993). PN nitration of GLT1/GLAST blocks their transport activity, thus increasing spinal glutamate that contributes to rapid alterations in synaptic transmission (for review, see Salvemini et al., 2011). In contradistinction to the GT regulation of extracellular glutamate homeostasis, GS is pivotal in intracellular glutamate metabolic fate and in the CNS, located mainly in astrocytes that protect neurons against excitotoxicity by removing excess ammonia and glutamate and converting them into glutamine (Kugler, 1993). PN nitrates and inactivates GS (on Tyr 160), thus maintaining neuronal excitation (for review, see Salvemini et al., 2011). Thus, by removing $P N$ and preventing GT and GS nitration, PNDCs plausibly "reset" optimal glutamatergic neurotransmission. In addition to their inactivation, downregulation of the GT

trocytes versus microglial cells in paclitaxel-induced neuropathic pain remains controversial (Weng et al., 2005; Cata et al., 2006a, 2008; Ledeboer et al., 2006; Peters et al., 2007; F. Y. Zheng et al., 2011; Zhang et al., 2012) and will be best understood as selective inhibitors are developed. Notably, minocycline, a nonselective inhibitor of both microglia (Tikka et al., 2001) and astrocytes (Raghavendra et al., 2003) activation, attenuates paclitaxelinduced mechanical hypersensitivity and downregulation of both GLAST and GLT-1 in spinal cord (Zhang et al., 2012). However, it is possible that the beneficial effects of minocycline are mediated through its antioxidant (Kraus et al., 2005) and potent PN scavenging (Schildknecht et al., 2011) properties. Our findings revealed that glial cells may be important for at least two PNdependent mechanisms in spinal cord. First, PN regulates spinal glia-derived proinflammatory and anti-inflammatory cytokines, favoring the former and correlating with increased astrocyteassociated GFAP and microglia-associated OX-42 expression. MnTE-2-PyP ${ }^{5+}$ blocked the increases in TNF- $\alpha$ and IL- $1 \beta$, but enhanced anti-inflammatory IL-4 and IL-10 production. The mechanism(s) behind such regulatory function(s) are unknown. However, IL-10 and IL-4 expression are NO-dependent in other settings (Chang et al., 1997; Chen et al., 2010). Therefore, increased NOS activity alone could stimulate IL-10 and IL-4; but concurrent increases in SO from NADPH oxidase activation and/or nitration/inactivation of MnSOD may deplete $\mathrm{NO}$ in favor of PN formation and dampen NO-driven IL-10 and IL-4 expression, observed in spinal cords during paclitaxel-induced neuropathic pain, also contributes to alterations in glutamatergic neurotransmission (Weng et al., 2005; Cata et al., 2006a; Zhang et al., 2012). We demonstrated that in addition to their ability to block neuropathic pain, PNDCs reverse it suggesting a role for $\mathrm{PN}$ in its maintenance; whether mechanisms of PN in this setting are similar to those that underlie its involvement in the development of neuropathic pain is not known warranting further work.

Although our studies focused on neuropathological changes in spinal cord, we cannot exclude likely contributions of PN in the periphery. The limited ability of paclitaxel to cross the blood brain barrier (Glantz et al., 1995) suggests the possibility that neuropathological changes observed in spinal cord result from changes in primary afferent fibers (Kapadia and LaMotte, 1987; Aldskogius et al., 1999) or by spinal release of factors from injured sensory neurons (Tsuda et al., 2005), rather than by direct paclitaxel effect on spinal cord. Paclitaxel-induced peripheral sensory neuropathy is associated with neuropathological processes that include increased mitotoxicity/mitochondrial dysfunction (Flatters and Bennett, 2006; H. Zheng et al., 2010, 2011; Xiao and Bennett, 2012) and peripheral loss of intradermal end nerve fibers (Siau et al., 2006; Bennett et al., 2011). Evidence suggests paclitaxel induces mitochondrial dysfunction that results in a chronic axonal energy deficit in sensory afferents, increasing their spontaneous discharge and initiating pathways ultimately leading to activation of central sensitization mecha- 
A

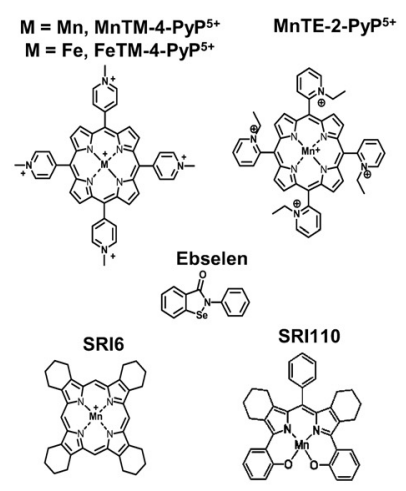

B

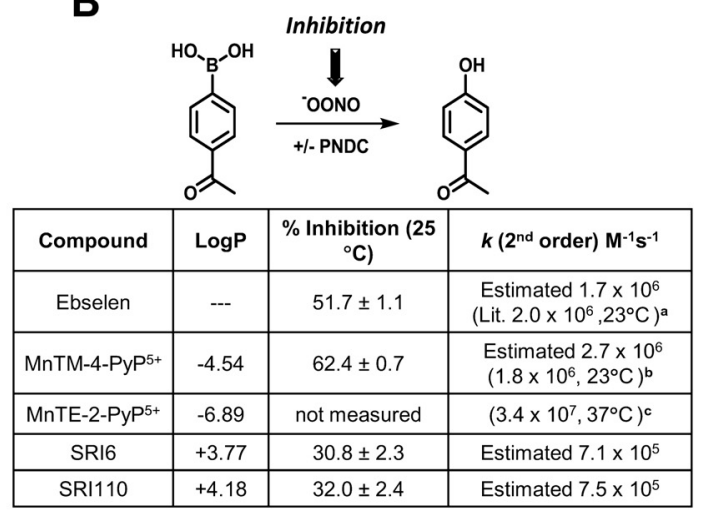

C

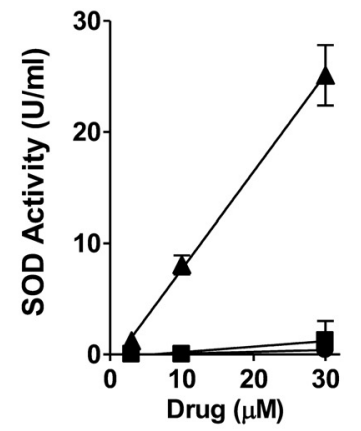

Figure 8. Evaluation of SRI6 and SRI110 activities versus MnTM-4-PyP ${ }^{5+}, \mathrm{MnTE}-2-\mathrm{PyP}^{5+}$ and Ebselen. $\boldsymbol{A}$, Structures of PNDCs and Ebselen. $\boldsymbol{B}$, Inhibition of boronic acid oxidation assay. $\boldsymbol{C}$,

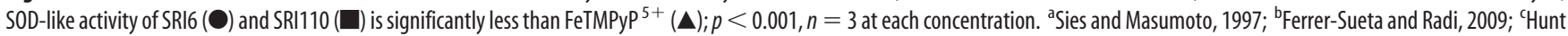
et al., 1997.

A

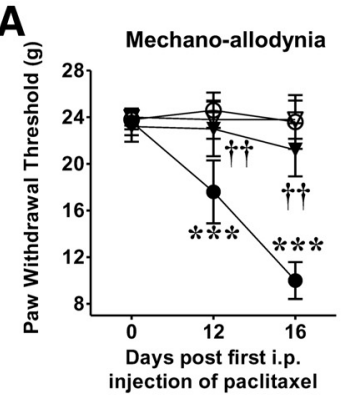

E

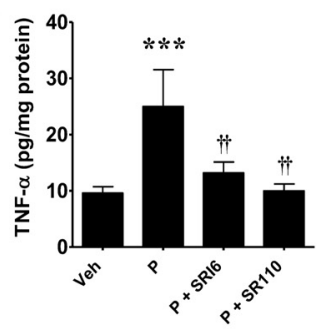

B

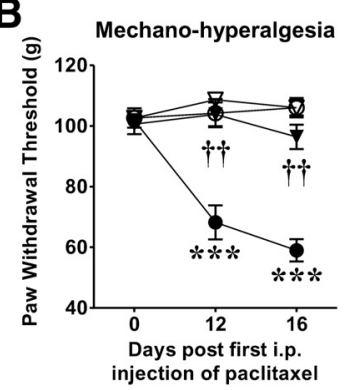

F

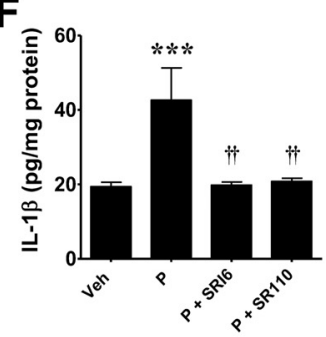

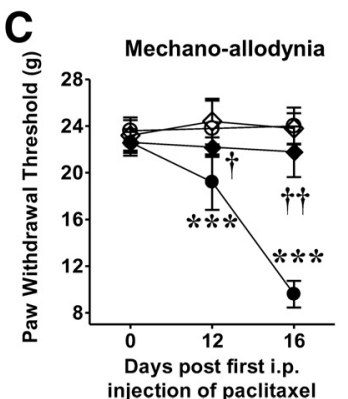

G

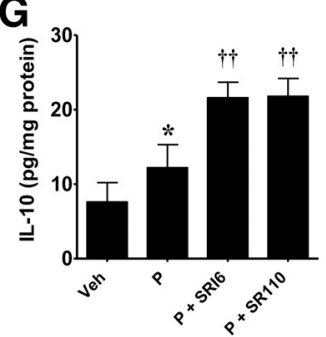

D

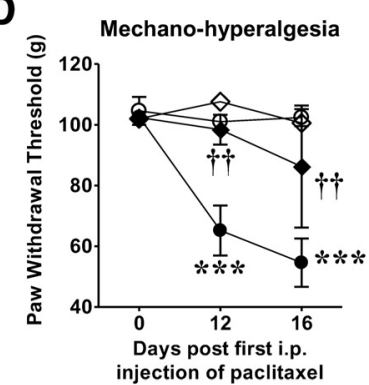

H

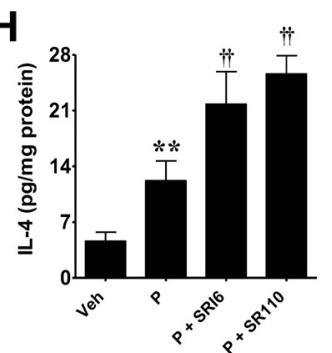

Figure 9. Oral delivery of "SO-sparing" PNDCs blocks the development of neuropathic pain. $\boldsymbol{A}-\boldsymbol{D}$, Compared with the vehicle group $(O)$, paclitaxel $(\boldsymbol{O})$ induced mechano-allodynia $(\boldsymbol{A}, \boldsymbol{C})$ and mechano-hyperalgesia $(\boldsymbol{B}, \boldsymbol{D})$ that was blocked by daily $(D 0-D 15)$ oral delivery $\left(30 \mathrm{mg} \cdot \mathrm{kg}^{-1} \cdot \mathrm{d}^{-1}\right)$ of SRI6 $(\nabla ; A, B)$ or SRI110 $(\bullet ; C, D)$. SRI6 $(\nabla)$ or SRI110 $(\diamond)$ alone did not affect withdrawal thresholds in vehicle groups $(\boldsymbol{A}-\boldsymbol{D})$. $\boldsymbol{E}, \boldsymbol{F}$, Compared with vehicle, paclitaxel increased TNF- $\alpha$ and IL-1 $\beta(\boldsymbol{E}, \boldsymbol{F})$ that was significantly attenuated by SRI6 or SRI110 $\left(30 \mathrm{mg} \cdot \mathrm{kg}^{-1} \cdot \mathrm{d}^{-1}\right) \cdot \boldsymbol{G}, \boldsymbol{H}$, Compared with vehicle, paclitaxel increased anti-inflammatory IL-10 and IL-4 $(\boldsymbol{G}, \boldsymbol{H})$, which was substantially enhanced by SRI6 or SRI110 $\left(30 \mathrm{mg} \cdot \mathrm{kg}^{-1} \cdot \mathrm{d}^{-1}\right)$. Results are expressed as mean \pm SD for 5 animals. Behavioral data were analyzed by two-tailed, two-way repeated-measures ANOVA with Bonferroni comparisons. Data for cytokine production were analyzed by two-tailed, one-way ANOVA with Dunnett's comparisons to paclitaxel group. ${ }^{*} p<0.05,{ }^{* *} p<0.01$ or ${ }^{* * *} p<0.001$ for paclitaxel versus vehicle; ${ }^{\dagger} p<0.01$ or ${ }^{\text {tt }} p<0.001$ for paclitaxel versus paclitaxel + SRI6 or SRI110.

nisms that promote allodynia and hyperalgesia (Flatters and Bennett, 2006; Bennett, 2010). The triggering events leading to mitotoxicity are unknown; however, $\mathrm{PN}$ is a candidate since mitochondria constitute a primary locus for the intracellular formation and reactions of PN and increased formation of intra- and extramitochondrially formed PN can lead to mitochondrial dysfunction and mitotoxicity in several experimental models (Radi et al., 2002). Another possible mechanism includes peripheral increase in circulating cytokines such as TNF- $\alpha$ that migrate across the blood brain barrier; promoting inflammation and nitroxidative stress in spinal cord. In breast cancer patients, paclitaxel has been shown to increase plasma levels of several cytokines (Tsavaris et al., 2002). Moreover, adriamycin, which does not cross the blood brain barrier, elicits inflammation and nitroxidative stress in the brain via increased plasma [TNF- $\alpha$ ]; which is attenuated by systemic administration of antioxidants (Joshi et al., 2010).

While pharmacological probes such as $\mathrm{FeTM}_{4} \mathrm{PyP}^{5+}$ and MnTE-2-PyP ${ }^{5+}$ have excellent catalytic activities toward decomposing $\mathrm{SO}$ and $\mathrm{PN}$, they are not orally bioavailable and may thus have limited therapeutic potential for chronic pain states. In addition, they are equally reactive with both $\mathrm{SO}$ and $\mathrm{PN}$, which may interfere with some of the important physiological roles of SO (Massaad and Klann, 2010). To address these problems, we have retooled these catalysts for PNDC selectivity and oral activity (Rausaria et al., 2011a,b). SRI6 and SRI110, when given orally, blocked neuropathic pain development and reduced proinflammatory cytokine production, while enhancing anti-inflammatory cytokine production. Further, by virtue of this new design, SRI6 and SRI110 are significantly harder to reduce than electron 
poor compounds like Mn-TM-4-PyP ${ }^{5+}$. Thus the metal-based reduction potentials of these more electron rich catalysts are out of the range useful for SOD activity (SRI6 $\mathrm{E}^{\mathrm{o}}<-0.2 \mathrm{~V}$ with +0.3 V optimal for SOD activity) (Batinic-Haberle et al., 2010), but well within range for the decomposition of $\mathrm{PN}\left(\mathrm{ONOO}^{-}, 2 \mathrm{H}^{+} /\right.$ $\cdot \mathrm{NO}_{2} \mathrm{E}^{\circ \prime}=1.4 \mathrm{~V}$ and $\mathrm{ONOO}^{-}, 2 \mathrm{H}^{+} / \mathrm{NO}_{2}^{-} \mathrm{E}^{\circ \prime}=1.2 \mathrm{~V}$ ) (Koppenol et al., 1992). Our findings provide critical information necessary for confirming $\mathrm{PN}$ as a new therapeutic target for attenuating a major dose-limiting toxicity of paclitaxel without impeding on its beneficial antitumor effects.

\section{References}

Aldskogius H, Liu L, Svensson M (1999) Glial responses to synaptic damage and plasticity. J Neurosci Res 58:33-41.

Batinic-Haberle I, Reboucas JS, Spasojevich I (2010) Superoxide dismutase mimics: chemistry, pharmacology and therapeutic potential. Antioxid Redox Signal 13:877-918.

Beckman JS, Beckman TW, Chen J, Marshall PA, Freeman BA (1990) Apparent hydroxyl radical production by peroxynitrite: implications for endothelial injury from nitric oxide and superoxide. Proc Natl Acad Sci U S A 87:1620-1624.

Bennett GJ (2010) Pathophysiology and animal models of cancer-related painful peripheral neuropathy. Oncologist 15 [Suppl 2]:9-12.

Bennett GJ, Liu GK, Xiao WH, Jin HW, Siau C (2011) Terminal arbor degeneration-a novel lesion produced by the antineoplastic agent paclitaxel. Eur J Neurosci 33:1667-1676.

Bensinger RE, Johnson CM (1981) Luminol assay for superoxide dismutase. Anal Biochem 116:142-145.

Cata JP, Weng HR, Chen JH, Dougherty PM (2006a) Altered discharges of spinal wide dynamic range neurons and down-regulation of glutamate transporter expression in rats with paclitaxel-induced hyperalgesia. Neuroscience 138:329-338.

Cata JP, Weng HR, Lee BN, Reuben JM, Dougherty PM (2006b) Clinical and experimental findings in humans and animals with chemotherapyinduced peripheral neuropathy. Minerva Anestesiol 72:151-169.

Cata JP, Weng HR, Dougherty PM (2008) The effects of thalidomide and minocycline on taxol-induced hyperalgesia in rats. Brain Res 1229: $100-110$.

Chang RH, Feng MH, Liu WH, Lai MZ (1997) Nitric oxide increased interleukin-4 expression in T lymphocytes. Immunology 90:364-369.

Chen Y, Boettger MK, Reif A, Schmitt A, Uçeyler N, Sommer C (2010) Nitric oxide synthase modulates CFA-induced thermal hyperalgesia through cytokine regulation in mice. Mol Pain 6:13.

Dahan L, Sadok A, Formento JL, Seitz JF, Kovacic H (2009) Modulation of cellular redox state underlies antagonism between oxaliplatin and cetuximab in human colorectal cancer cell lines. Br J Pharmacol 158:610-620.

Decraene D, Smaers K, Gan D, Mammone T, Matsui M, Maes D, Declercq L, Garmyn M (2004) A synthetic superoxide dismutase/catalase mimetic (EUK-134) inhibits membrane-damage-induced activation of mitogenactivated protein kinase pathways and reduces p53 accumulation in ultraviolet B-exposed primary human keratinocytes. J Invest Dermatol 122:484-491.

DeLeo JA, Yezierski RP (2001) The role of neuroinflammation and neuroimmune activation in persistent pain. Pain 90:1-6.

Dixon WJ (1980) Efficient analysis of experimental observations. Annu Rev Pharmacol Toxicol 20:441-462.

Doyle T, Bryant L, Muscoli C, Cuzzocrea S, Esposito E, Chen Z, Salvemini D (2010) Spinal NADPH oxidase is a source of superoxide in the development of morphine-induced hyperalgesia and antinociceptive tolerance. Neurosci Lett 483:85-89.

Farquhar-Smith P (2011) Chemotherapy-induced neuropathic pain. Curr Opin Support Palliat Care 5:1-7.

Ferrer-Sueta G, Radi R (2009) Chemical biology of peroxynitrite: kinetics, diffusion, and radicals. ACS Chem Biol 4:161-177.

Flatters SJ, Bennett GJ (2006) Studies of peripheral sensory nerves in paclitaxel-induced painful peripheral neuropathy: evidence for mitochondrial dysfunction. Pain 122:245-257.

Fries DM, Paxinou E, Themistocleous M, Swanberg E, Griendling KK, Salvemini D, Slot JW, Heijnen HF, Hazen SL, Ischiropoulos H (2003) Expression of inducible nitric-oxide synthase and intracellular protein tyrosine nitration in vascular smooth muscle cells: role of reactive oxygen species. J Biol Chem 278:22901-22907.

Glantz MJ, Choy H, Kearns CM, Mills PC, Wahlberg LU, Zuhowski EG, Calabresi P, Egorin MJ (1995) Paclitaxel disposition in plasma and central nervous systems of humans and rats with brain tumors. J Natl Cancer Inst 87:1077-1081.

Görg B, Wettstein M, Metzger S, Schliess F, Häussinger D (2005) Lipopolysaccharide-induced tyrosine nitration and inactivation of hepatic glutamine synthetase in the rat. Hepatology 41:1065-1073.

Hunt JA, Lee J, Groves JT (1997) Amphiphilic peroxynitrite decomposition catalysts in liposomal assemblies. Chem Biol 4:845-858.

Itamochi H, Oishi T, Shimada M, Sato S, Uegaki K, Naniwa J, Nonaka M, Terakawa N, Kigawa J, Harada T (2011) Inhibiting the mTOR pathway synergistically enhances cytotoxicity in ovarian cancer cells induced by etoposide through upregulation of c-Jun. Clin Cancer Res 17:4742-4750.

Joshi G, Aluise CD, Cole MP, Sultana R, Pierce WM, Vore M, St Clair DK, Butterfield DA (2010) Alterations in brain antioxidant enzymes and redox proteomic identification of oxidized brain proteins induced by the anti-cancer drug adriamycin: implications for oxidative stress-mediated chemobrain. Neuroscience 166:796-807.

Kapadia SE, LaMotte CC (1987) Deafferentation-induced alterations in the rat dorsal horn: I. Comparison of peripheral nerve injury vs. rhizotomy effects on presynaptic, postsynaptic, and glial processes. J Comp Neurol 266:183-197.

Kimura H, Nakano M (1988) Highly sensitive and reliable chemiluminescence method for the assay of superoxide dismutase in human erythrocytes. FEBS Lett 239:347-350.

Koppenol WH, Moreno JJ, Pryor WA, Ischiropoulos H, Beckman JS (1992) Peroxynitrite, a cloaked oxidant formed by nitric oxide and superoxide. Chem Res Toxicol 5:834-842.

Kraus RL, Pasieczny R, Lariosa-Willingham K, Turner MS, Jiang A, Trauger JW (2005) Antioxidant properties of minocycline: neuroprotection in an oxidative stress assay and direct radical-scavenging activity. J Neurochem 94:819-827.

Kriedt CL, Baldassare J, Shah M, Klein C (2010) Zinc functions as a cytotoxic agent for prostate cancer cells independent of culture and growth conditions. J Exp Ther Oncol 8:287-295.

Kugler P (1993) Enzymes involved in glutamatergic and GABAergic neurotransmission. Int Rev Cytol 147:285-336.

Lacroix M, Leclercq G (2004) Relevance of breast cancer cell lines as models for breast tumours: an update. Breast Cancer Res Treat 83:249-289.

Ledeboer A, Liu T, Shumilla JA, Mahoney JH, Vijay S, Gross MI, Vargas JA, Sultzbaugh L, Claypool MD, Sanftner LM, Watkins LR, Johnson KW (2006) The glial modulatory drug AV411 attenuates mechanical allodynia in rat models of neuropathic pain. Neuron Glia Biol 2:279-291.

Ledeboer A, Jekich BM, Sloane EM, Mahoney JH, Langer SJ, Milligan ED, Martin D, Maier SF, Johnson KW, Leinwand LA, Chavez RA, Watkins LR (2007) Intrathecal interleukin-10 gene therapy attenuates paclitaxelinduced mechanical allodynia and proinflammatory cytokine expression in dorsal root ganglia in rats. Brain Behav Immun 21:686-698.

Macmillan-Crow LA, Cruthirds DL (2001) Invited review: manganese superoxide dismutase in disease. Free Radic Res 34:325-336.

Massaad CA, Klann E (2010) Reactive Oxygen Species in the Regulation of Synaptic Plasticity and Memory. Antioxid Redox Signal 14:2013-2054.

McCord JM, Fridovich I (1969) Superoxide dismutase. An enzymic function for erythrocuprein (hemocuprein). J Biol Chem 244:6049-6055.

Milligan ED, Watkins LR (2009) Pathological and protective roles of glia in chronic pain. Nat Rev Neurosci 10:23-36.

Miñana MD, Kosenko E, Marcaida G, Hermenegildo C, Montoliu C, Grisolía S, Felipo V (1997) Modulation of glutamine synthesis in cultured astrocytes by nitric oxide. Cell Mol Neurobiol 17:433-445.

Moncada S, Palmer RM, Higgs EA (1991) Nitric oxide: physiology, pathophysiology, and pharmacology. Pharmacol Rev 43:109-142.

Muscoli C, Cuzzocrea S, Ndengele MM, Mollace V, Porreca F, Fabrizi F, Esposito E, Masini E, Matuschak GM, Salvemini D (2007) Therapeutic manipulation of peroxynitrite attenuates the development of opiateinduced antinociceptive tolerance in mice. J Clin Invest 117:3530-3539.

Muscoli C, Doyle T, Dagostino C, Bryant L, Chen Z, Watkins LR, Ryerse J, Bieberich E, Neumman W, Salvemini D (2010) Counter-regulation of opioid analgesia by glial-derived bioactive sphingolipids. J Neurosci 30:15400-15408.

Peters CM, Jimenez-Andrade JM, Jonas BM, Sevcik MA, Koewler NJ, 
Ghilardi JR, Wong GY, Mantyh PW (2007) Intravenous paclitaxel administration in the rat induces a peripheral sensory neuropathy characterized by macrophage infiltration and injury to sensory neurons and their supporting cells. Exp Neurol 203:42-54.

Polomano RC, Mannes AJ, Clark US, Bennett GJ (2001) A painful peripheral neuropathy in the rat produced by the chemotherapeutic drug, paclitaxel. Pain 94:293-304.

Radi R, Cassina A, Hodara R, Quijano C, Castro L (2002) Peroxynitrite reactions and formation in mitochondria. Free Radic Biol Med 33:1451-1464.

Raghavendra V, Tanga F, DeLeo JA (2003) Inhibition of microglial activation attenuates the development but not existing hypersensitivity in a rat model of neuropathy. J Pharmacol Exp Ther 306:624-630.

Ramos KM, Lewis MT, Morgan KN, Crysdale NY, Kroll JL, Taylor FR, Harrison JA, Sloane EM, Maier SF, Watkins LR (2010) Spinal upregulation of glutamate transporter GLT-1 by ceftriaxone: therapeutic efficacy in a range of experimental nervous system disorders. Neuroscience 169:1888-1900.

Randall LO, Selitto JJ (1957) A method for measurement of analgesic activity on inflamed tissue. Arch Int Pharmacodyn Ther 111:409-419.

Rausaria S, Kamadulski A, Rath NP, Bryant L, Chen Z, Salvemini D, Neumann WL (2011a) Manganese(III) complexes of bis(hydroxyphenyl)dipyrromethenes are potent orally active peroxynitrite scavengers. J Am Chem Soc 133:4200-4203.

Rausaria S, Ghaffari MM, Kamadulski A, Rodgers K, Bryant L, Chen Z, Doyle T, Shaw MJ, Salvemini D, Neumann WL (2011b) Retooling manganese(III) porphyrin-based peroxynitrite decomposition catalysts for selectivity and oral activity: a potential new strategy for treating chronic pain. J Med Chem 54:8658-8669.

Salter M, Knowles RG, Moncada S (1991) Widespread tissue distribution, species distribution and changes in activity of $\mathrm{Ca}(2+)$-dependent and $\mathrm{Ca}(2+)$-independent nitric oxide synthases. FEBS Lett 291:145-149.

Salvemini D, Jensen MP, Riley DP, Misko TP (1998) Therapeutic manipulations of peroxynitrite. Drug News Perspect 11:204-214.

Salvemini D, Little JW, Doyle T, Neumann WL (2011) Roles of reactive oxygen and nitrogen species in pain. Free Radic Biol Med 51:951-966.

Schildknecht S, Pape R, Müller N, Robotta M, Marquardt A, Bürkle A, Drescher M, Leist M (2011) Neuroprotection by minocycline due to direct and specific scavenging of peroxynitrite. J Biol Chem 286:4991-5002.

Schoeniger-Skinner DK, Ledeboer A, Frank MG, Milligan ED, Poole S, Martin D, Maier SF, Watkins LR (2007) Interleukin-6 mediates lowthreshold mechanical allodynia induced by intrathecal HIV-1 envelope glycoprotein gp120. Brain Behav Immun 21:660-667.

Shah MR, Kriedt CL, Lents NH, Hoyer MK, Jamaluddin N, Klein C, Baldassare J (2009) Direct intra-tumoral injection of zinc-acetate halts tumor growth in a xenograft model of prostate cancer. J Exp Clin Cancer Res 28:84.

Siau C, Xiao W, Bennett GJ (2006) Paclitaxel- and vincristine-evoked painful peripheral neuropathies: loss of epidermal innervation and activation of Langerhans cells. Exp Neurol 201:507-514.

Sies H, Masumoto H (1997) Ebselen as a glutathione peroxidase mimic and as a scavenger of peroxynitrite. Adv Pharmacol 38:229-246.

Sikora A, Zielonka J, Lopez M, Joseph J, Kalyanaraman B (2009) Direct oxidation of boronates by peroxynitrite: mechanism and implications in fluorescence imaging of peroxynitrite. Free Radic Biol Med 47:14011407.

Simons JM, Hart BA, Ip Vai Ching TR, Van Dijk H, Labadie RP (1990) Metabolic activation of natural phenols into selective oxidative burst agonists by activated human neutrophils. Free Radic Biol Med 8:251-258.

Smith CD, Carson M, van der Woerd M, Chen J, Ischiropoulos H, Beckman JS (1992) Crystal structure of peroxynitrite-modified bovine $\mathrm{Cu}, \mathrm{Zn}$ superoxide dismutase. Arch Biochem Biophys 299:350-355.
Spasojević I, Chen Y, Noel TJ, Fan P, Zhang L, Rebouças JS, St Clair DK, Batinić-Haberle I (2008) Pharmacokinetics of the potent redoxmodulating manganese porphyrin, $\mathrm{MnTE}-2-\mathrm{PyP}(5+)$, in plasma and major organs of B6C3F1 mice. Free Radic Biol Med 45:943-949.

Størkson RV, Kjørsvik A, Tjølsen A, Hole K (1996) Lumbar catheterization of the spinal subarachnoid space in the rat. J Neurosci Methods $65: 167-172$

Swift S, Ellison AR, Kassner P, McCaffery I, Rossi J, Sinclair AM, Begley CG, Elliott S (2010) Absence of functional EpoR expression in human tumor cell lines. Blood 115:4254-4263.

Szabó C, Ischiropoulos H, Radi R (2007) Peroxynitrite: biochemistry, pathophysiology and development of therapeutics. Nat Rev Drug Discov 6:662-680

Takagi N, Logan R, Teves L, Wallace MC, Gurd JW (2000) Altered interaction between PSD-95 and the NMDA receptor following transient global ischemia. J Neurochem 74:169-178.

Tikka T, Fiebich BL, Goldsteins G, Keinanen R, Koistinaho J (2001) Minocycline, a tetracycline derivative, is neuroprotective against excitotoxicity by inhibiting activation and proliferation of microglia. J Neurosci 21:2580-2588.

Trotti D, Rossi D, Gjesdal O, Levy LM, Racagni G, Danbolt NC, Volterra A (1996) Peroxynitrite inhibits glutamate transporter subtypes. J Biol Chem 271:5976-5979.

Trotti D, Rolfs A, Danbolt NC, Brown RH Jr, Hediger MA (1999) SOD1 mutants linked to amyotrophic lateral sclerosis selectively inactivate a glial glutamate transporter. Nat Neurosci 2:848.

Tsavaris N, Kosmas C, Vadiaka M, Kanelopoulos P, Boulamatsis D (2002) Immune changes in patients with advanced breast cancer undergoing chemotherapy with taxanes. Br J Cancer 87:21-27.

Tsuda M, Inoue K, Salter MW (2005) Neuropathic pain and spinal microglia: a big problem from molecules in "small" glia. Trends Neurosci 28:101-107.

Uppu RM, Squadrito GL, Pryor WA (1996) Acceleration of peroxynitrite oxidations by carbon dioxide. Arch Biochem Biophys 327:335-343.

Wang ZQ, Porreca F, Cuzzocrea S, Galen K, Lightfoot R, Masini E, Muscoli C, Mollace V, Ndengele M, Ischiropoulos H, Salvemini D (2004) A newly identified role for superoxide in inflammatory pain. J Pharmacol Exp Ther 309:869-878.

Watkins LR, Milligan ED, Maier SF (2001) Glial activation: a driving force for pathological pain. Trends Neurosci 24:450-455.

Weng HR, Aravindan N, Cata JP, Chen JH, Shaw AD, Dougherty PM (2005) Spinal glial glutamate transporters downregulate in rats with taxolinduced hyperalgesia. Neurosci Lett 386:18-22.

Wu ZZ, Lu HP, Chao CC (2010) Identification and functional analysis of genes which confer resistance to cisplatin in tumor cells. Biochem Pharmacol 80:262-276.

Xiao WH, Bennett GJ (2012) Effects of mitochondrial poisons on the neuropathic pain produced by the chemotherapeutic agents, paclitaxel and oxaliplatin. Pain 153:704-709.

Zhang H, Yoon SY, Dougherty PM (2012) Evidence that spinal astrocytes but not microglia contribute to the pathogenesis of paclitaxel-induced painful neuropathy. J Pain 13:293-303.

Zheng FY, Xiao WH, Bennett GJ (2011) The response of spinal microglia to chemotherapy-evoked painful peripheral neuropathies is distinct from that evoked by traumatic nerve injuries. Neuroscience 176:447-454.

Zheng H, Xiao, WH, Bennett, GJ (2010) Mitotoxicity as the cause of the oainful peripheral neuropathies evoked by the chemotherapeutics, paclitaxel and oxaliplatin. IASP 13th World Congress on Pain, Montreal, Quebec, Abstract PW097.

Zheng H, Xiao WH, Bennett GJ (2011) Functional deficits in peripheral nerve mitochondria in rats with paclitaxel- and oxaliplatin-evoked painful peripheral neuropathy. Exp Neurol 232:145-161. 